\title{
Algorithms and practical fluorescence models of the photosynthetic apparatus of red cyanobacteria and Cryptophyta designed for the fluorescence detection of red cyanobacteria and cryptophytes
}

\author{
M. Beutler ${ }^{1,2, *}$, K. H. Wiltshire ${ }^{3}$, C. Reineke ${ }^{2}$, U.-P. Hansen ${ }^{4}$ \\ ${ }^{1}$ Max-Planck-Institut (MPI) für biophysikalische Chemie, Abteilung molekulare Biologie, Am Fassberg 11, \\ 37077 Göttingen, Germany \\ ${ }^{2}$ Max-Planck-Institut (MPI) für Limnologie, August-Thienemann-Straße 2, 24302 Plön, Germany \\ ${ }^{3}$ Biologische Anstalt Helgoland, In der Stiftung Alfred-Wegner-Institut, Postfach 180, 27483 Helgoland, Germany \\ ${ }^{4}$ Zentrum für Biochemie und Molekularbiologie (ZBM), Universität Kiel, Leibnizstr. 11, 24098 Kiel, Germany
}

\begin{abstract}
In fluorometric phytoplankton analysis, the detection of red cyanobacteria is hampered by acclimation processes of the cyanobacterial photosynthetic apparatus and spectral interferences with Cryptophyta. In order to overcome these problems, a simplified energy distribution model accounting for energy pathways in the red cyanobacterial photosynthetic apparatus and the apparatus of Cryptophyta was developed. Mathematical equations were derived that enabled calculation of the pigment content of Cryptophyta and red cyanobacteria in the same sample. Phytoplankton samples were excited with 7 excitation wavelengths and measured at 4 detection wavelengths $(600,620,650$ and $685 \mathrm{~nm}$ ) in vivo. A non-linear fit procedure accounted for variations in the fluorescence excitation spectra of red cyanobacteria and Cryptophyta in the presence of other phytoplankton fluorescence signals. Comparison with chemical pigment estimations verified that the fluorometric pigment estimation yielded reasonable results, even in the presence of energy-state transitions.
\end{abstract}

KEY WORDS: Phycobilisome - Energy distribution model - Phycoerythrin - Phycocyanin · Cyanobacteria $\cdot$ Fluorescence $\cdot$ Cryptophyta

\section{INTRODUCTION}

In stratified pelagic systems, chlorophyll (hereafter referred to as 'chl') maxima of red cyanobacteria (containing the red pigment phycoerythrin) are often found in deep water layers. In these so-called deep chlorophyll maxima, red cyanobacteria are very abundant due to their ability to survive in this chromatic niche, e.g. Van Den Hoek et al. 1995, Lampert \& Sommer 1997). This niche is usually situated below the thermocline in regions of high nutrient concentrations and low light intensities. Red cyanobacteria are important primary producers and they can cause toxic blooms; in reservoir drinking water these can cause fatalities in humans (Leboulanger et al. 2002). As deep chlorophyll maxima are not usually visible at the surface, their occurrence is often overlooked. By enabling easy depth profiling, new optical probe technology (spectral fluorescence analysis) can facilitate detection and quantification of deep phytoplankton and, specifically, red cyanobacteria maxima (Yentsch \& Yentsch 1979, Yentsch \& Phinney 1985, Cowles et al. 1993, Lee et al. 1994, Kolbowski \& Schreiber 1995, Desiderio et al. 1997, Gerhardt \& Bodemer 1998, Seppala \& Balode 1998, Beutler et al. 2002b, Leboulanger et al. 2002, Millie et al. 2002). Acclimation processes of the photosynthetic apparatus of phytoplankton due to environmental changes can affect fluorometric analysis (Beutler et al. 2003). Another difficulty is the differentiation of Cryptophyta and their common companions, the 
cyanobacteria (Becker et al. 2002). As they both can contain phycoerythrin (PE), this can lead to errors in the identification of red cyanobacteria. To solve these problems it was imperative to obtain a quantitative description of the optical and energetic transfer processes in cyanobacteria and Cryptophyta.

In cyanobacterial species containing $\mathrm{PE}$, the phycobilisomes (PBSs) consist of phycobiliproteins, PE, phycocyanin (PC) and in the core regions of PBS, allophycocyanin. Linker polypetides are present in the PBSs (they are non-pigmented, with the exception of the large core linker $L_{\mathrm{CM}}$ ).

Energy transfer processes in PBSs containing PE are analogous to those in PBSs containing no PE (see Beutler et al. 2003), and the main energy transfer process from PE via PC to allophycocyanin is a downhill Förster-transfer. PE from cyanobacteria emits at a maximum emission wavelength between 580 and $600 \mathrm{~nm}$ in vivo in addition to $\mathrm{PC}$, allophycocyanin, photosystem (PS) II and PS I (Beutler et al. 2003).

Cryptophyta use phycobiliproteins as light harvesting antennae in addition to a chl $C_{2}$ chl a antenna. Seven different phycobilins are known (Lichtle et al. 1992, McKay et al. 1992). Phycobilins and chl $c_{2}$ chl a antenna are associated with PS II (McKay et al. 1992). This implies that most antennae chl is associated with PS II. Ecologically important freshwater species like some Rhodomonas species and Cryptomonas ovata contain $\mathrm{PE}_{566}$ with an absorption maximum at $566 \mathrm{~nm}$ and a fluorescence emission maximum at $617 \mathrm{~nm}$ (MacColl \& Guard-Friar 1987, Rowan 1989, Becker et al. 2002). In Cryptophyta, much less is known about the energy transfer than in cyanobacteria. However, it can be assumed that energy is transferred downhill from PE to the chl antennae (Maccoll \& Berns 1978, Lichtle et al. 1980, Harnischfeger \& Herold 1981) under moderate illumination.

Like all microalgae, red cyanobacteria and Cryptophyta possess the ability to acclimate their photosynthetic apparatus to environmental conditions. The acclimation in red cyanobacteria (Müller et al. 1993, Reuter \& Müller 1993, Tandeau de Marsac \& Houmard 1993, Bryant 1995), as a result of shifts in light or nutrient conditions, is mediated by changes in the PE and PC content in the PBS and PS I:PS II ratio, analogous to blue cyanobacteria as given in Beutler et al. (2003). When cyanobacteria become limited by iron, PBSs may be degraded, and a pigment protein complex similar to CP43' is expressed by the isiA (chlorophyll binding protein) gene (iron stress induced) (Riethman \& Sherman 1988, Straus 1994, Falkowski \& Raven 1997, Bibby 2001).
In Cryptophyta, the size of the PE and chl $c_{2}$ chl a antennae relative to PS II can change due to light or nutrient shifts (Sciandra et al. 2000). As for blue cyanobacteria, short-term 'energy state transitions' are also known in red cyanobacteria and Cryptophyta (see Harnischfeger \& Herold 1981, Williams \& Allen 1987, Biggins \& Bruce 1989, Campbell et al. 1998, van Thor et al. 1998, Beutler et al. 2003). This variability of the Cryptophyta and red cyanobacterial photosynthetic apparatus can cause problems in detection and discrimination of phytoplankton based on fluorescence (Beutler et al. 2002b). For blue cyanobacteria, these problems were overcome by the approach described in Beutler et al. (2003). The problems that arise from isiA accumulation in blue cyanobacteria were discussed in Beutler et al. (2003), and are also valid for red cyanobacteria. In spite of the variations in the ratio of the pigment PC to chl a caused by acclimation to varying environmental conditions, it was possible to determine PC, chl $a$ and PS II centre concentrations by the measurement of fluorescence excitation spectra with just 2 emission wavelengths (650 and $685 \mathrm{~nm}$ ). This was achieved by the development of a new fit procedure based on a simplified energy distribution model of the cyanobacterial photosynthetic apparatus.

In this study, the problem of spectral fluorometric analysis of red cyanobacteria was investigated. Special consideration of Cryptophyta containing $\mathrm{PE}_{566}$ was achieved by developing simple fluorescence models. This required the extension of the fit procedure and the fluorometer of Beutler et al. (2003).

\section{MATERIALS AND METHODS}

Growth experiments. Different growth conditions similar to those in Beutler et al. (2003) were employed in order to provide a great variety of fluorescence phenotypes for testing the models developed in Appendices 1 \& 2 . In all growth experiments, the cyanobacterium Synechococcus rubescens and the Cryptophyta Cryptomonas ovata were grown in 0.71 WC growth media (Guillard \& Lorenzen 1972) at a temperature of $18^{\circ} \mathrm{C}$. The cultures were bubbled with air. The light intensity for growth in the empty vessels was $20 \mu \mathrm{mol}$ photons $\mathrm{m}^{-2} \mathrm{~s}^{-1}$ unless otherwise stated. For Cryptomonas ovata, all parameters were kept constant apart from the growth light intensities.

After an initial growth period of $14 \mathrm{~d}$, experiments were carried out. The chl content was determined by HPLC-analyses, and the PE and PC content was deter-

Abbreviations: Chl, chlorophyll; $F_{0}$, dark fluorescence; $F_{\mathrm{m}}$ maximal fluorescence; $F$, steady-state fluorescence; $F_{\mathrm{v}}$, variable fluorescence; HPLC, high performance liquid chromatography; isiA, chlorophyll-binding protein; LED, light-emitting diode; PBS, phycobilisome; PC, phycocyanin; PE, phycoerythrin; PS, photosystem; REE, rapid exciton equilibrium 
mined spectrophotometrically. The number of active PS II centres was measured by evaluating oxygen evolution under flash-light illumination (see Beutler et al. 2003) in cultures of red cyanobacteria. The pigment determinations were replicated 3 times. Diluted phytoplankton samples were measured in the multi-channel fluorometer (see below).

Growth of cyanobacteria under 8 different light intensities was achieved by covering culture vessels with different grey filter combinations (LEE Standard 209, 210, 211, 298, LEE filters, Great Britain) placed in front of a light tube (L 58W/11-860, Lumilux-Daylight). Intensity was measured with the PhAR sensor Hansatech QRT 1 (Hansatech) in the covered glass vessels. In the experiments, the following light intensities were used: $3,6,9,13,18,25,35$ and $50 \mu \mathrm{mol}$ photons $\mathrm{m}^{-2} \mathrm{~s}^{-1}$. The organisms did not grow at light intensities higher than $50 \mu \mathrm{mol}$ photons $\mathrm{m}^{-2} \mathrm{~s}^{-1}$. Thus, higher intensities seem to be of minor ecological importance and were excluded from the investigations. The nutrient solution was WC-medium (Guillard \& Lorenzen 1972).

The effect of different nitrate, phosphate and total nutrient concentrations on fluorescence was evaluated in the following 3 experiments.

Growth under different nitrate and phosphate concentrations: Synechococcus rubescens was cultivated in WC-medium (Guillard \& Lorenzen 1972) with nitrate concentrations of $0.1,0.58,2.9,5.9,8.8,12,17.6$ or $24 \mathrm{mmol} \mathrm{l}^{-1}$, and phosphate concentrations of 0.0087 , $0.02,0.05,0.1,0.25,0.5,1$ and $2 \mathrm{mmol} \mathrm{l}^{-1} \mathrm{~K}_{2} \mathrm{HPO}_{4}$.

Different cyanobacterial and Cryptophyta species: Lyngbya maior, Planktothrix rubescens, Oscillatoria redekii, P. redekii, Synechococcus rubescens (all cyanobacteria) and Cryptomonas (3 different species) were obtained from the SAG collection in Göttingen, Germany.

Effect of total nutrient concentration on fluorescence: Variation of total nutrient concentrations was achieved by growing algae in mixtures of WC (Guillard \& Lorenzen 1972) and BG11 medium (Rippka \& Herdman 1992). The relative amounts of BG11 medium in the 8 vessels were $0,12.5,25,50,62.5,75$, 87.5 and $100 \%$.

Aging cultures. To investigate the effect of the age of the batch cultures on pigment composition and fluorescence, Synechococcus rubescens was grown in a $10 \mathrm{l}$ flask. After a week of growth, fluorescence measurements were carried out.

Fluorescence measurements. Basically, the set-up for the determination of norm spectra for laboratory and in vivo experiments is similar to the bench-top fluorometer described in Beutler et al. (2003), supplemented by a 4 th detection wavelength. The measuring times and evaluation procedures were also identical to those of Beutler et al. (2003). The set-up enabled the measurement of dark fluorescence $\left(F_{0}\right)$, maximal fluorescence $\left(F_{\mathrm{m}}\right)$, and variable fluorescence $\left(F_{\mathrm{v}}\right)$ according to the definition of van Kooten \& Snel (1990) at 7 fluorescence excitation wavelengths $(370,430,470$, 525, 570, 590, $610 \mathrm{~nm}$ ). Light-emitting diode (LED) light was passed through the same optics as described in Beutler et al. (2003). The peak detection wavelengths of the 4 detectors were defined by band-pass filter combinations, with the following peak wavelength/half-width combinations (listed from detector to sample): $600 \mathrm{~nm} / 10 \mathrm{~nm}$ : Calflex x, Balzers, Liechtenstein $_{i}+$ band pass interference filter; $600 \mathrm{~nm} / 10 \mathrm{~nm}$, Dr. Anders; GFH 681, Göttinger Farbfilter, Germany; + OG 590, long-pass dye filter, Schott Glas, Germany; + band-pass interference filter $600 \mathrm{~nm} / 10 \mathrm{~nm}$, Dr. Anders; $620 \mathrm{~nm} / 10 \mathrm{~nm}$ : Calflex $\mathrm{x}_{i}+$ band pass interference filter, $620 \mathrm{~nm} / 10 \mathrm{~nm}$ Dr. Anders; + long pass GFH 681, Göttinger Farbfilter; + OG 590, long-pass dye filter, Schott Glas; + interference filter $620 \mathrm{~nm} / 10 \mathrm{~nm}$, Dr. Anders; $650 \mathrm{~nm} / 10 \mathrm{~nm}$ : $685 \mathrm{~nm} / 10 \mathrm{~nm}$ : see Beutler et al. (2003) for details.

Four laser diodes (Hitachi HL6501MG, $658 \mathrm{~nm}$ ) with a diffuser in order to prevent light spatterings were placed opposite the LEDs. They provided an additional actinic light of $3000 \mu \mathrm{mol}$ photons $\mathrm{m}^{-2} \mathrm{~s}^{-1}$ over an area of $227 \mathrm{~mm}^{2}$ in the cuvette. They were also used for the detection of state transitions. The light intensity of the laser diodes was voltage controlled. The samples were illuminated 15 min prior to the measurement.

Determination of chl concentrations. Concentrations of chl $a$ and $\operatorname{chl} C_{2}$ (required for calibrating the fluorometer, see norm spectra) were determined according to Wiltshire et al. (1998) using HPLC.

Phycobilin determination. The amount of phycobilins in algal suspensions was determined in a wet chemical spectrophotometric analysis as described in Beutler et al. (2003). The equations for the determination of PC and PE are given in Bennett \& Bogorad (1973). These equations also hold for $\mathrm{PE}_{566}$ of Cryptophyta. The concentration of Cryptophyta $\mathrm{PE}_{566}$ is given in red cyanobacterial PE equivalents.

\section{RESULTS}

\section{Red cyanobacteria grown with different pigmentation}

Synechococcus rubescens was subject to various growth conditions (see above) in order to obtain an estimate of the range of variations in pigmentation and to obtain cyanobacteria with different excitation spectra for the test of the model given in Appendix 1. The influence of light intensity during growth is shown in Fig. 1A. The PE:chl a ratio increased at high light intensity, whereas the PS II:chl a ratio and the 

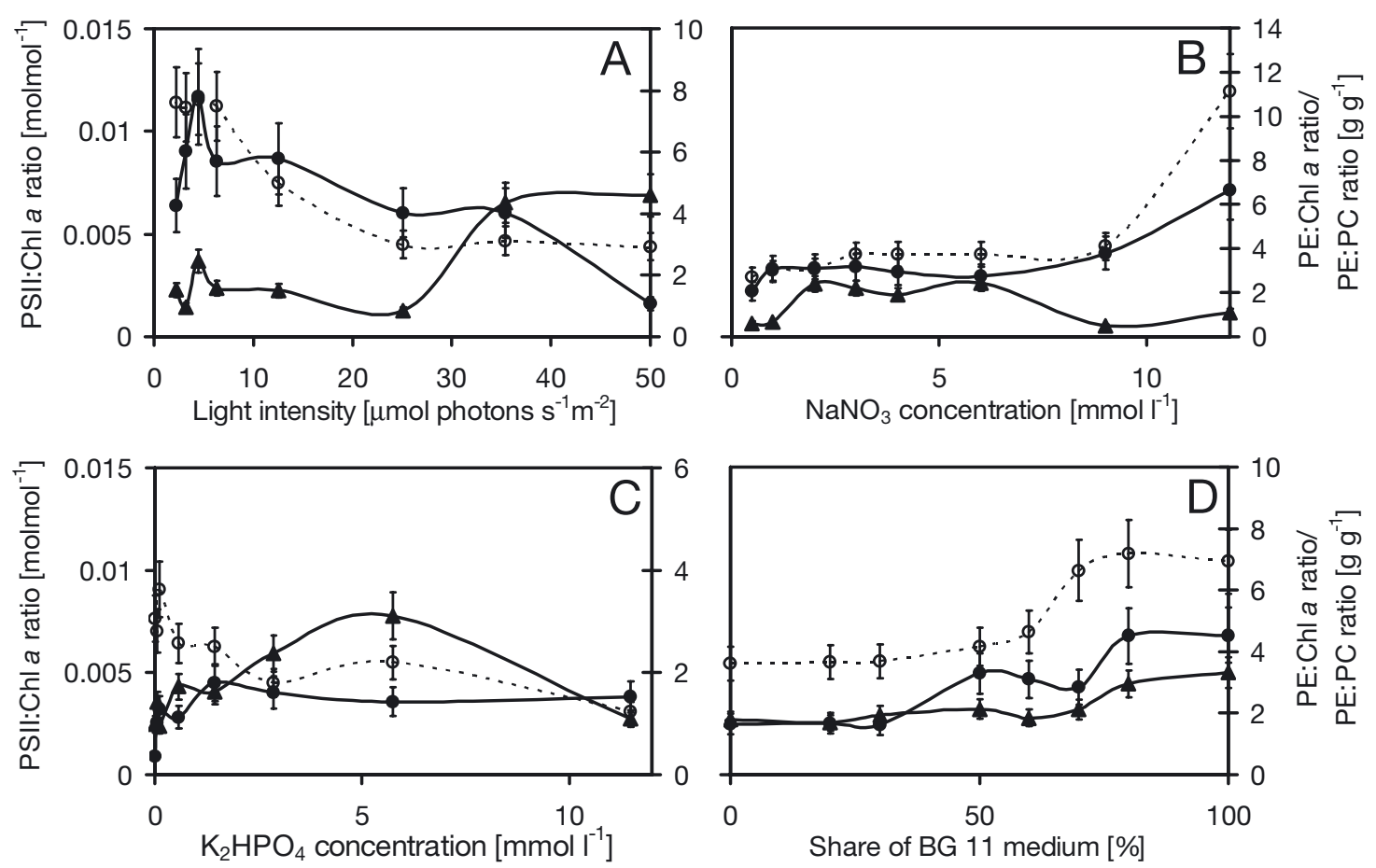

Fig. 1. Synechococcus rubescens. Change of the pigment ratios and number of photosystem (PS) II reaction centres under variation of growth conditions in $S$. rubescens as caused by variation of (A) light intensities required for growth; $(\mathrm{B}) \mathrm{NaNO}_{3}$ concentration; (C) $\mathrm{K}_{2} \mathrm{HPO}_{4}$ concentration; (D) share of BG11 medium (Rippka \& Herdman 1992) in culture. ( $-\mathbf{\Delta}$ ) Ratio of phycoerythrin (PE) to chl $a_{i}(-)$ ) ratio of number PS II centres to chl a concentration; (O- - - O) ratio of PE to phycocyanin (PC). Chl was determined by HPLC; PE and PC by chemical analysis; and PS II centres by oxygen flash yield measurement

PE:PC ratio decreased. A variable ratio of PS II:chl a indicates a changed ratio of PS II to PS I. Nitrate (Fig. 1B) had little influence over a wide range of concentrations. Above $10 \mathrm{mM} \mathrm{NaNO}$, the PE:PC and PS II:chl a ratios increased strongly. Phosphate (Fig. 1C) led to a maximum PE:chl ratio at starting concentrations of ca. $6 \mathrm{mmol} \mathrm{l}^{-1}$. The PE:PC ratio and PS II:chl a ratio obtained maximum values at lower concentrations and showed a moderate decrease at higher concentrations. The effect of total nutrient concentration in the starting medium is depicted in Fig. 1D. All 3 pigment ratios increased at higher total nutrient concentrations. In the growth experiments shown in Fig. 1, the PE:PC and PS II:chl a ratios are closely correlated.

Species dependences under the same growth conditions are shown in Fig. 2A for pigment ratios of PE, PC, PS II and chl of 5 cyanobacterial species. Due to very low pigment concentrations in 4 cultures, it was not possible to determine the number of PS II reaction centres with sufficient accuracy.

The variations of the pigment ratios shown in Figs. 1 \& $2 \mathrm{~A}$ ranged as follows: the ratio of $\mathrm{PE}$ :chl between 0.7 and $6 \mathrm{~g} \mathrm{~g}^{-1}$, the PE:PC ratio between 1 and $11 \mathrm{~g} \mathrm{~g}^{-1}$, and the PS II:chl changed 4-fold in Fig. 1.

\section{Growth of Cryptophyta under different light intensities and growth of different species}

In order to test the fluorescence model given in Appendix 2 for Cryptophyta, and to evaluate the variability of their fluorescence spectra, Cryptophyta were grown under different light intensities. The organisms did not grow at light intensities higher than $50 \mu \mathrm{mol}$ photons $\mathrm{m}^{-2} \mathrm{~s}^{-1}$. Thus, higher intensities seem to be of minor ecological importance and were excluded from the investigations. Due to the relative simplicity of the model for Cryptophyta (Appendix 2) compared to that for red cyanobacteria (Appendix 1), a smaller number of cultures was necessary. Furthermore, testing the model did not require the determination of PS II reaction centre concentrations. Fig. $2 \mathrm{~B}$ shows that the $\mathrm{chl} \mathrm{C}_{2}$ : $\mathrm{chl}$ a ratio reached a low plateau between 6.3 and $25 \mu \mathrm{mol}$ photons $\mathrm{m}^{-2} \mathrm{~s}^{-1}$, and the ratio of PE:chl a decreased strongly after a peak at $6.3 \mu \mathrm{mol}$ photons $\mathrm{m}^{-2} \mathrm{~s}^{-1}$.

Species dependences of PE:chl a ratios and $\mathrm{chl} C_{2}$ :chl a ratios are shown for 3 different $\mathrm{PE}$-containing Cryptophyta grown under the same conditions as in Fig. 2A. In Fig. 2B,C, the PE:chl a ratio varied from 0.25 to $1.5 \mathrm{~g} \mathrm{~g}^{-1}$, and the ratio of $\mathrm{chl} \mathrm{C}_{2}$ :chl a varied between 0.4 and $1.2 \mathrm{~g} \mathrm{~g}^{-1}$. The different types of pigmentation 

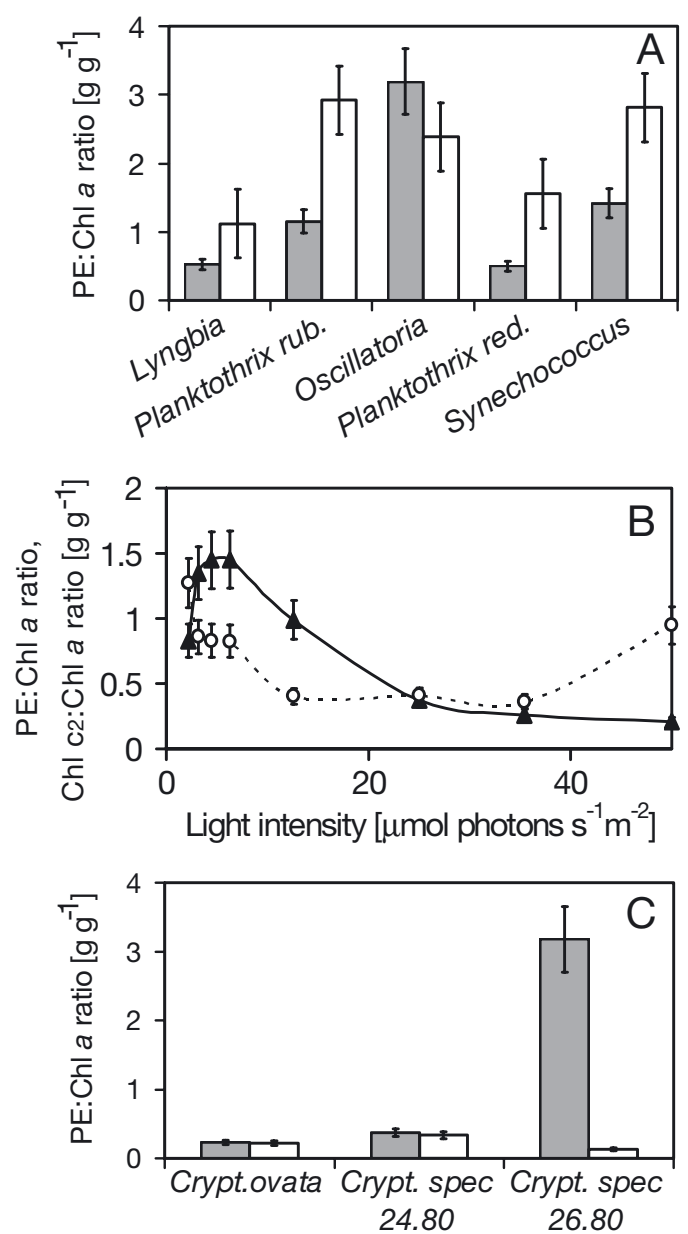

Fig. 2. (A) Pigment ratios of 5 different cyanobacterial species. Open bars: phycoerythrin:phycocyanin (PE:PC) ratio; grey bars: PE centre:chl a concentration ratio). Lyngbya: L. maior; Planktothrix rub: P. rubescens; Oscillatoria: O. redekii; Planktothrix red.: P. redekii; Synechococcus: S. rubescens. (B) Change of the PE:chl a $(\boldsymbol{\Delta})$ and $\operatorname{chl} C_{2}$ :chl a (O--O) ratios in Cryptophyta under variation of growth light intensities. (C) PE:chl $a$ and $\mathrm{chl} \mathrm{C}_{2}$ :chl $a$ ratios of 3 different Cryptophyta (open bars: PE:PC ratio; grey bars: PE centre:chl a concentration ratio). Chl was determined by HPLC; PE and PC by chemical analysis; and PS II centres by oxygen flash yield measurement

provided by different growth conditions described in this section were used in the following investigations.

\section{Simplified models of energy transfer in the antennae of red cyanobacteria and Cryptophyta}

Fig. 3 shows the pigments of the photosynthetic apparatus of cyanobacteria and Cryptophyta and the flow of energy between them. The mathematical description of these models is presented in Appendix 1 for red cyanobacteria and in Appendix 2 for Cryptophyta.

\section{Validation of the fluorescence model of the red cyanobacterial apparatus}

In order to test the fluorescence model for the red cyanobacterial apparatus and the parametrical description of Appendix 1, the concentrations of PE, PC, and chl and PS II centres of red cyanobacteria calculated from fluorescence data ( $y$-axis of Fig. 4) were compared with those obtained from HPLC analysis and chemical analysis (abscissa of Fig. 4). The fluorometric analysis was based on Eq. (A7) for PE, Eq. (A9) for PC, Eq. (A11a) for the PS II reaction centres, and Eq. (A15) for chl estimates. A linear regression of the data on pigmentation types of Figs. $1 \mathrm{~A}-\mathrm{D}$ and $2 \mathrm{~A}$ at 3 different concentrations resulted in a ratio very close to the one with a high correlation coefficient in Fig. 4. The mean standard errors for pigment estimation in Fig. 4 were in the range of the errors of the reference estimates. Calculations were made under the simplifying assumption that $\mathrm{c}_{1, \mathrm{chl}}$ (Eq. A16) is equal to zero. This only decreased the precision by $1 \%$ and enabled the use of the simpler and faster fit in Appendix 3. This validity also demonstrates the validity of the 3 assumptions in Appendix 1 by means of Eqs. (A7), (A9), (A11a) \& (A15).

\section{Comparison of the calculated and measured phycoerythrin, chlorophyll and photosystem II centre concentrations in Cryptophyta}

Analogous to red cyanobacteria (Fig. 4), the model for Cryptophyta given in Appendix 2 was verified by calculating linear regressions for fluorometrically determined PE- (Eq. A27), and chl- (Eq. A28) estimates versus the chemically determined concentrations of the samples in Fig. 2B,C. Fig. 5 shows that the estimation of pigments by fluorescence coincided with the reference estimates.

The norm spectra and the fit procedure have to fulfil all requirements to carry out the fit procedure described in Beutler et al. (2003), i.e. norm spectra are constant or, if not constant, the changes in curve-shape induced by environmental conditions must be described by a single parameter. The new approach in Appendix 3 demanded the extension of these requirements to the norm spectra at the 4 emission wavelengths of $600,620,650$ and $685 \mathrm{~nm}$. The mean excitation spectra of the algae with pigmentation in Figs. 1 \& 2 are shown in Fig. 6. The spectra were normalised to excitation using $570 \mathrm{~nm}$. The highest standard deviation $(10 \%)$ of the mean spectra occurred for the spectra of Cryptophyta at an emission wavelength of $685 \mathrm{~nm}$, with excitation at $470 \mathrm{~nm}$. This is sufficiently small for the algal estimation. 

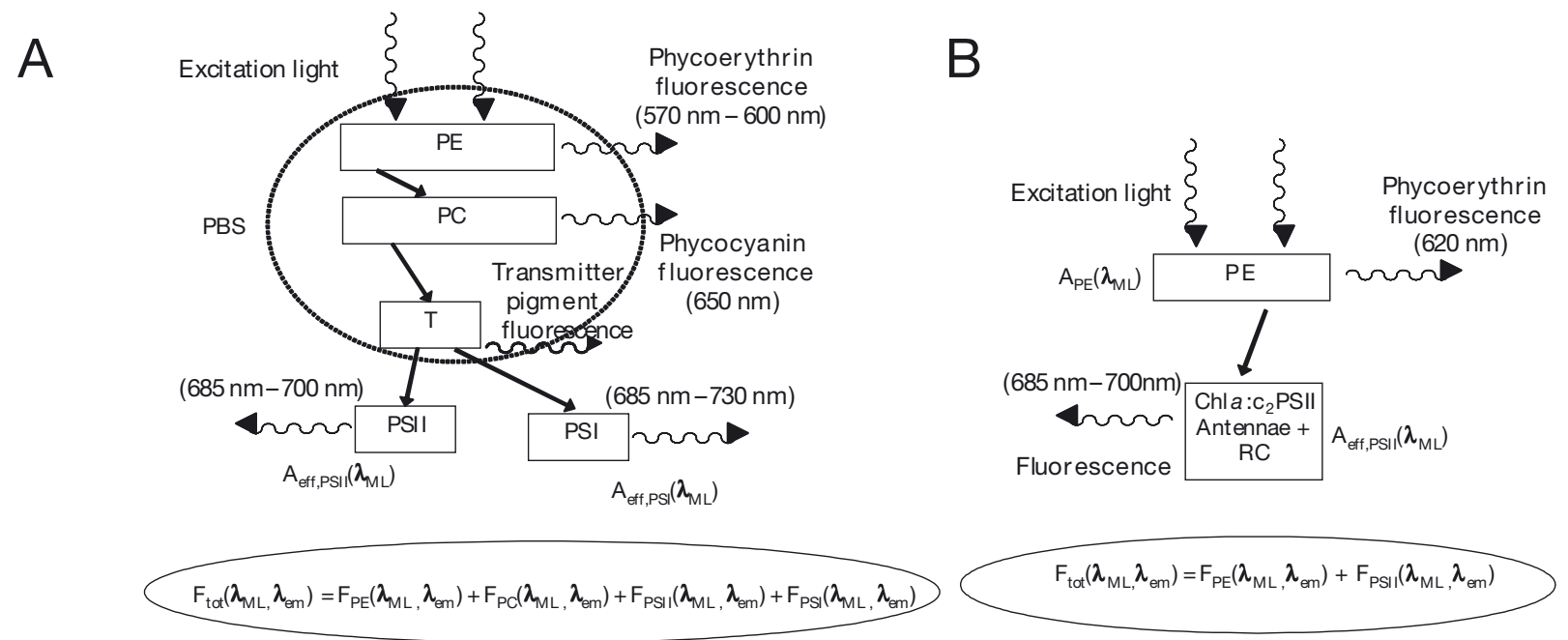

Fig. 3. Simplified model of absorption and fluorescence emission processes in photosystems (PSs). $A_{\text {eff,PSII }}\left(\lambda_{\mathrm{ML}}\right), A_{\text {eff,PSI }}\left(\lambda_{\mathrm{ML}}\right)$ : effective absorption cross-section (m²) of PS II and PS I; $A_{\mathrm{PE}}\left(\lambda_{\mathrm{ML}}\right), A_{\mathrm{PC}}\left(\lambda_{\mathrm{ML}}\right)$ : Phycoerythrin (PE) and phycocyanin (PC) absorption cross-section $\left(\mathrm{m}^{2}\right) ; F_{\mathrm{PE}}\left(\lambda_{\mathrm{ML}}, \lambda_{\mathrm{em}}\right), F_{\mathrm{PC}}\left(\lambda_{\mathrm{ML}}, \lambda_{\mathrm{em}}\right), F_{\mathrm{PS} \mathrm{II}}\left(\lambda_{\mathrm{ML}}, \lambda_{\mathrm{em}}\right), F_{\mathrm{PS} \mathrm{I}}\left(\lambda_{\mathrm{ML}}, \lambda_{\mathrm{em}}\right)$ : total PE, PC, PS II and PS I fluorescence intensity; $\lambda_{\mathrm{ML}}$ : wavelength of measuring light; $\lambda_{\mathrm{em}}$ : fluorescence emission wavelength. (A) PE-containing organisms like Synechococcus rubescens. The core proteins of phycobilisome (PBS) (e.g. allophycocyanin) are classified as 'transmitter pigments' analogous to Beutler et al. (2003). The absorption and fluorescence properties of the 'transmitter pigments' (T) were neglected in the latter consideration and reduced to the function of energy transmitters. The fluorescence model is adapted and simplified from Zhou et al. (1992). (B) Cryptophyta containing PE (like Cryptomonas ovata). PS I fluorescence between 600 and $685 \mathrm{~nm}$ emission is assumed to be neglected (for details see Holzwarth (1991) and van Grondelle et al. (1994)
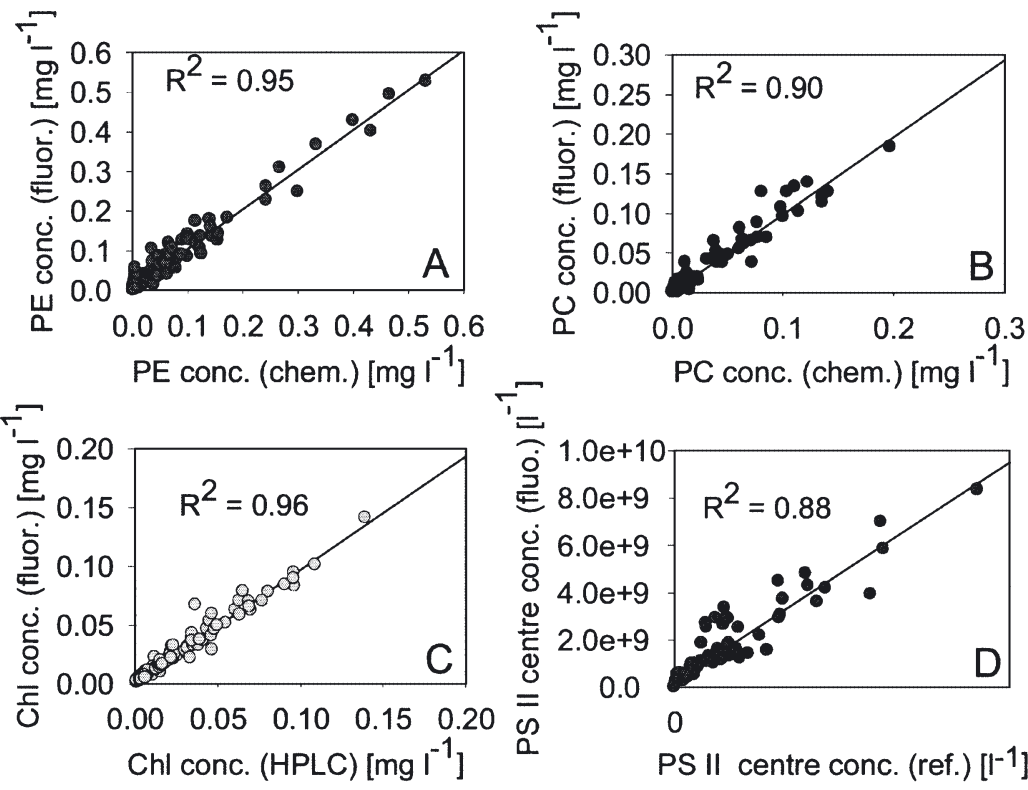

Fig. 4. Correlation between fluorometrically determined concentrations of (A) phycoerythrin (PE), (B) phycocyanin (PC), (C) chl $a$ and (D) photosystem (PS) II reaction centres in red cyanobacteria and chemically determined values. Data on the $y$-axis were calculated by means of Eqs. (A7), (A9), (A11a) \& (A23) (Appendix 1). The reference estimates on the $x$-axis were those shown in Figs. 1 \& 2A (except Fig. 4D uses reference estimates of Fig. 1 only). Data taken from Fig. 1 include experiments done at light intensities from 3 to $50 \mu \mathrm{mol}$ photons $\mathrm{m}^{-2} \mathrm{~s}^{-1}$, at different nutrient conditions as given on the abscissa of Fig. 1B-D and from different cyanobacterial species (Fig. 2A)
Another property of the mathematical fit procedure is its use of fixed fluorescence excitation spectra at emission wavelengths of 600 and $620 \mathrm{~nm}$ for Cryptophyta and red cyanobacteria (see Appendix 3). The mean emission spectra obtained from the pigmentation types depicted in Figs. 1 \& 2 were normalised to the fluorescence intensity emission at $600 \mathrm{~nm}$ (data not shown). The different treatments (Figs. $1 \& 2$ ) resulted in a standard deviation of $<3 \%$ for the mean spectra at an emission of $620 \mathrm{~nm}$. This implies that invariable emission spectra can be assumed at emission wavelengths of 600 and $620 \mathrm{~nm}$. At an emission wavelength of $685 \mathrm{~nm}$, the highest standard deviations (ca. 25\%) were found for both groups of algae. This variation can be handled by the fit procedure in Appendix 3.

\section{Identification in the presence of other phytoplankton}

Using the fit procedure given in Appendix 3 and the equations of the models in Appendices 1 and 2, it was possible to determine the amount of red cyanobacterial PE, PC and chl in the presence of other phytoplank- 

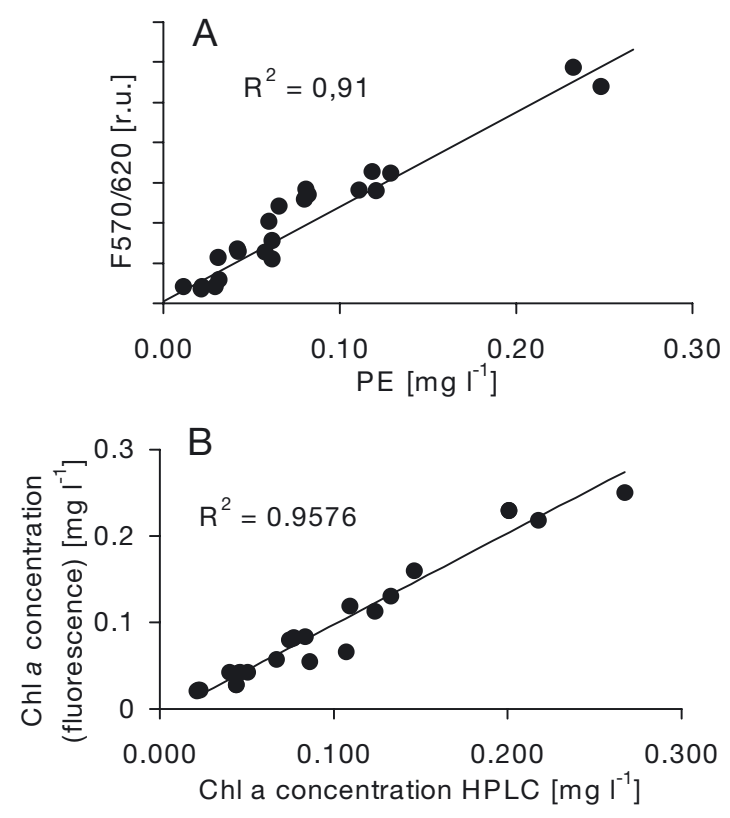

Fig. 5. Linear regressions of the calculated phycoerythrin (PE) and chl a concentrations in Cryptophyta from Eqs. (B10) \& (B11) (Appendix 2) on the reference estimates shown in Fig. 2B,C. (A) PE, (B) chl a

ton. In a dilution experiment, the contribution of the red algal group Synechococcus rubescens was changed, whereas other phytoplankton remained constantly abundant. Algal suspensions with constant chl contents of the green spectral group (Chlorella vulgaris), the blue spectral group (Synechococcus leopoliensis), the brown spectral group (Cyclotella sp.), the mixed spectral group (Cryptomonas sp.) and a varying $\mathrm{PE}, \mathrm{PC}$ and chl content of the red group were used. The constant chl a concentrations of the spectral algal groups were as follows: green $15 \mu \mathrm{g}$ $\mathrm{l}^{-1}$, blue $8 \mu \mathrm{g} \mathrm{l}^{-1}$, brown $10 \mu g \mathrm{l}^{-1}$, and mixed $4 \mu \mathrm{g}^{-1}$.

Fig. 7A shows that the correct linear increase of cyanobacterial chl a concentration was measured even in the presence of higher chl a concentrations of other phytoplankton. The same result was obtained for the cyanobacterial concentrations of phycobilins (Fig. 7B). The lowest total resolution of the system in terms total chl a concentration was $0.5 \mu \mathrm{g} \mathrm{l}^{-1}$ (with a standard deviation of $10 \%$ in 10 measurements; data not shown).
With higher concentrations of the red group, the estimation of the groups with smaller chl (Fig. 7A) and phycobilin content was slightly influenced (decrease at the right-hand side of the horizontal lines in Fig. 7).

\section{Aging of red cyanobacterial cultures}

Cyanobacteria in batch culture grow exponentially at the beginning of the culture period. This is comparable to the situation of a cyanobacterial bloom in situ. In the later stages of the growth period, they show a decrease in total chl due to nutrient limitation. The resulting changes in pigment concentrations were used for testing the fit procedure given in Appendix 3 and the validity of the equations of the model in Appendix 1. Spectra of the samples from the aging batch culture were determined in the fluorometer. In Fig. 8A, the evaluated PE and PC concentrations are shown. The pigment concentrations reached a maximum after $30 \mathrm{~d}$ growth. The overall estimation of PE and $\mathrm{PC}$ was in good agreement with the reference results. The measurement of $\mathrm{PE}$ had a smaller error than the estimation of PC (Fig. 8A). Fig. 8B depicts the measured chl and PS II reaction-centre concentration during the aging experiment. The decline of the chl and PS II reaction-centre concentration was slower than the decline of the phycobilins. Again, the overall
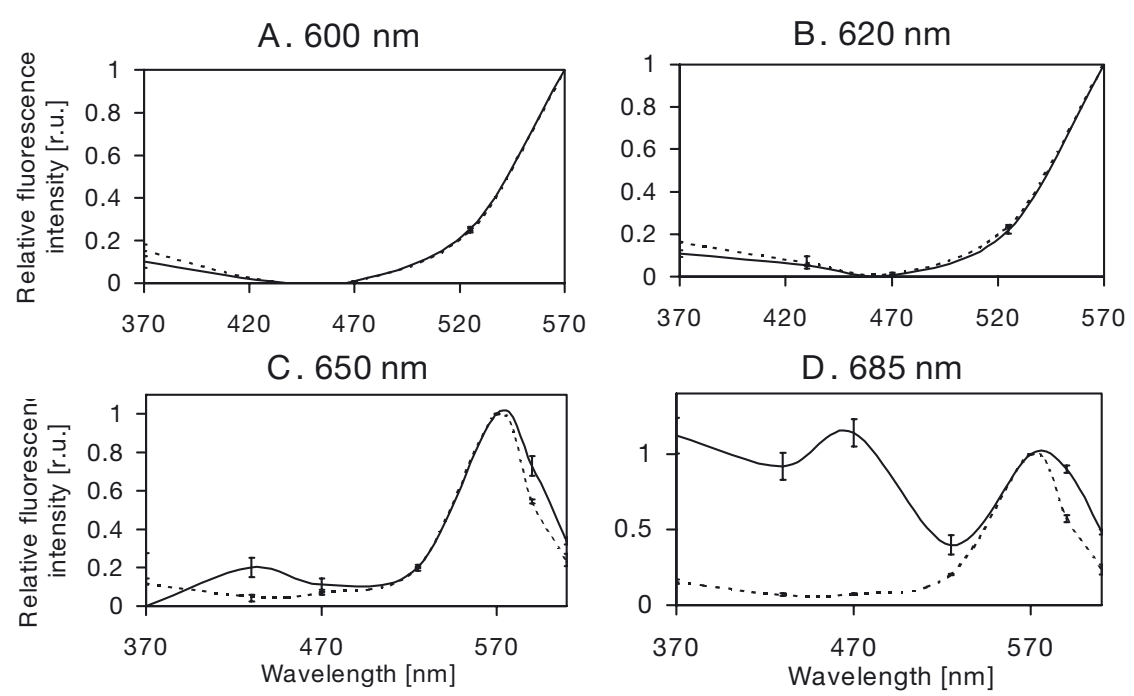

Fig. 6. Fluorescence excitation spectra of red cyanobacteria (dashed line) and Cryptophyta (solid line) obtained with the fluorometer set-up at 7 excitation wavelengths and normalised to fluorescence intensity at $570 \mathrm{~nm}$ excitation. The spectra are the mean normalised spectra of the organism with the pigment ratios shown Figs. 1 \& 2. (A) Spectrum at $600 \mathrm{~nm}$ detection wavelength, (B) spectrum at $620 \mathrm{~nm}$ detection wavelength, (C) spectrum at $650 \mathrm{~nm}$ detection wavelength, (D) spectrum at $685 \mathrm{~nm}$ detection wavelength. Error bars represent SD of the mean. Lines are interpolated manually between data points. Low SDs indicate a similar form of the spectra of one algal group and indicate a possible use of such mean spectra for the fit procedure presented in Appendix 3 


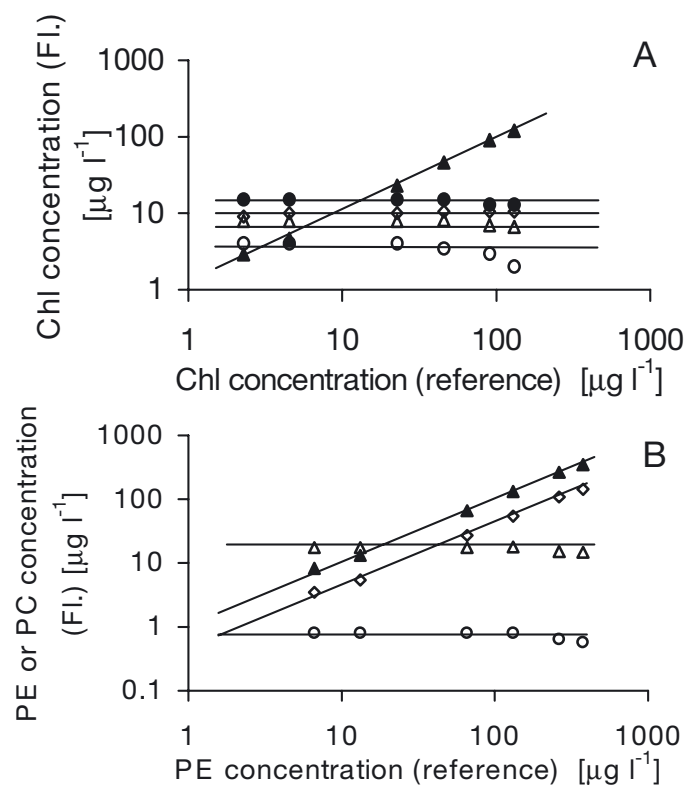

Fig. 7. Variation in contribution of the red algal group in the presence of other phytoplankton. (A) The fluorometrical estimate of the chl (green: $\bullet_{\text {; }}$ blue: $\Delta_{i}$ brown: $\diamond_{i}$ mixed: $O_{\text {; red: }}$ () content is shown versus the chl content measured with reference (HPLC). (B) Fluorometrical estimate of the phycoerythrin (PE) and phycocyanin (PC) concentration for the red, blue, and mixed group is shown versus the spectrochemically determined PE content of the red group. Red-PE: $\boldsymbol{\Delta}_{i}$ red-PC: $\diamond_{i}$ blue-PC: $\Delta_{i}$ Cryptophyta-PE: 0

estimations by fluorescence were highly correlated to the reference estimates. The determination of $\mathrm{chl}$ and PS II centres showed an underestimation at the beginning and an overestimation at the end of the growth period (Fig. 8B).

\section{Sensitivity to light-intensity (short-term acclimation)}

State transitions in green algae described the variable coupling of LHC (light-harvesting complex) antennae to PS II and presumably also to PS I. Red light moves LHC antennae to PS II; however, light intensity also has an influence on the association of LHC antennae and photosystems. In the case of PE- and PC-containing algae, also the coupling of PBS to PS II is variable.

Here, the influence of energy-state transitions induced by changes in light intensity on the estimates of fluorometric pigment concentration was investigated in red cyanobacteria (Fig. 9A) and in Cryptophyta (Fig. 9B). The fluorometric estimates of PE, PC, chl and PS II in red cyanobacteria, and PE and chl in Cryptophyta, were measured in order to determine their dependence on the light intensities. $F_{\mathrm{v} 570 / 685}$ : $F_{\mathrm{v} 470 / 685}$ is a measure of the ratio of the energy reaching PS II, via direct light absorption and via transfer from the PE to PS II $\left(F_{\mathrm{v} 570 / 685}\right)$, to the energy reaching PS II by light absorption of PS II directly $\left(F_{\mathrm{v} 470 / 685}\right)$. The energetic coupling of PBSs was highest (Fig. 9A) when the samples were adapted with light intensities in the range of the light required for growth (between 10 and $100 \mu \mathrm{mol}$ photons $\mathrm{m}^{-2} \mathrm{~s}^{-1}$ ). This is in remarkable correspondence with results of the investigations on blue cyanobacteria by (Campbell \& Öquist 1996) and Beutler et al. (2003). Low coupling to PS II (Fig. 9B) was found in dark-adapted and high-light-adapted cells. The variation in Fig. 9 of all fluorometric estimates in both organisms was less than $10 \%$. However, the dependence on light intensity was not very strong.

\section{DISCUSSION}

\section{Variation of cyanobacterial pigments and cryptophytal pigments}

The necessity for a special evaluation algorithm for red cyanobacteria and Cryptophyta becomes obvious when looking at the great variability of photosynthetic apparatus resulting from the dependence on growth conditions and on species, as shown in Figs. 1 \& 2A. Red cyanobacteria and Cryptophyta possess the ability to balance the photosynthetic apparatus to achieve a finely tuned overall photosynthetic process.

In red cyanobacteria, this variability became apparent in large changes of the ratios of PE:chl, PE:PC and
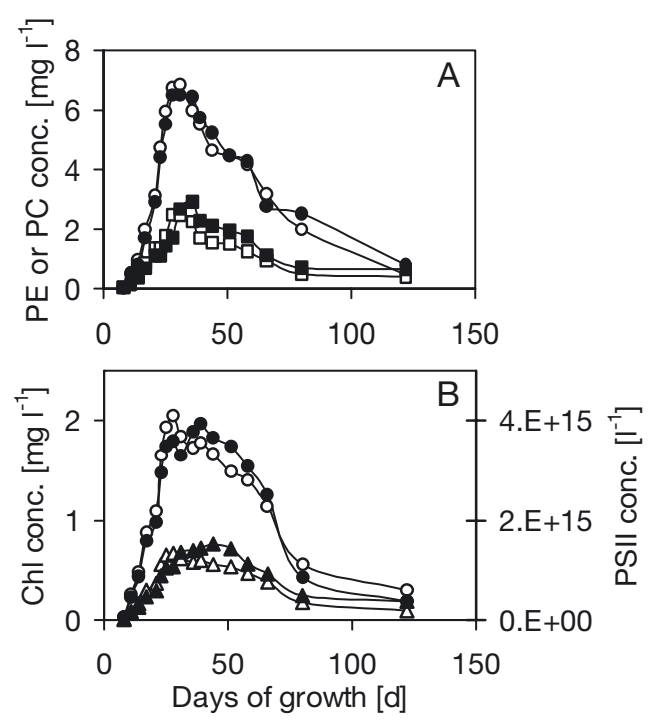

Fig. 8. Pigment concentrations measured at different ages (in days) of a red cyanobacterial batch culture. (A) Phycoerythrin (PE) and phycocyanin (PC) concentrations. (O) Fluorometrically determined PE concentration; $(\bullet)$ reference PE concentration; ( $\square$ ) fluorometrically determined PC concentration; (घ) reference PC concentration. (B) $(\Delta)$ Fluorometrically determined photosystem (PS) II reaction centres; (\) reference PS II reaction centres; (O) fluorometrically determined chl concentration, $(\bullet)$ reference chl concentration 


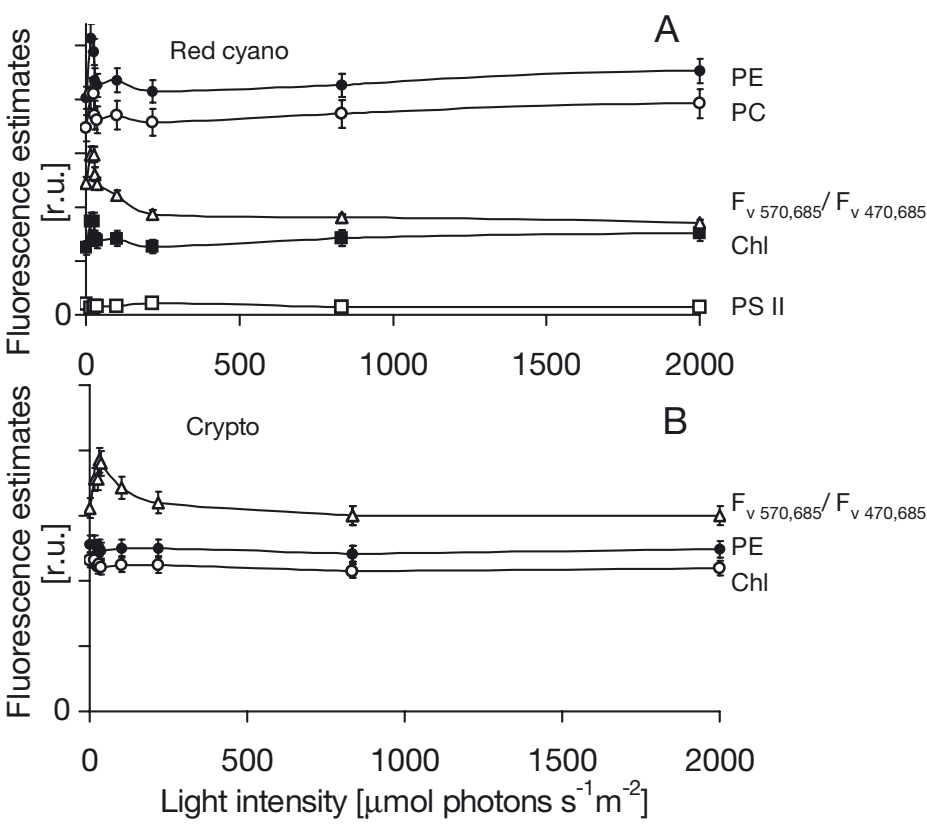

Fig. 9. (A) Synechococcus rubescens. Fluorometric pigment and photosystem (PS) II reaction centre estimates under light acclimation with different light intensities in $S$. rubescens. $(\Delta)$ Energetic coupling of phycobilisomes (PBSs) to PS II in terms of the ratio $F_{\mathrm{v} 570 / 685}: F_{\mathrm{v} 470 / 685}$ $(\bullet)$ fluorometrically determined phycoerythrin (PE) concentration (o) fluorometrically determined phycocyanin (PC) concentration; (匹) fluorometrically determined chl concentration; (ㅁ) fluorometrically determined PS II reaction centres. Dark-acclimation time prior to measurement was $1 \mathrm{~s}$ and acclimation time to light intensity was $15 \mathrm{~min}$. Three samples were averaged per data set. Measuring duration of $F_{0}$ and $F_{\mathrm{m}}$ was $1 \mathrm{~s}$. (B) Cryptomonas ovata. Fluorometric pigment centre estimates under light acclimation with different light intensities in C. ovata. $(\Delta)$ Energetic coupling of PBSs to PS II in terms of the ratio $F_{\mathrm{v} 570 / 685}: F_{\mathrm{v} 470 / 685 ;}(\mathrm{O})$ fluorometrically determined PE concentration; ( $\square)$ fluorometrically determined chl concentration. Dark acclimation time prior to measurement was $1 \mathrm{~s}$ and acclimation time to light intensity was $15 \mathrm{~min}$. Three samples were averaged per data set. Measuring duration of $F_{0}$ and $F_{\mathrm{m}}$ was $1 \mathrm{~s}$

PS II:chl (Figs. 1 \& 2A). The values of these ratios were similar to those reported in the literature (Kawamura et al. 1979, Schubert \& Hagemann 1990, Müller et al. 1993, Reuter \& Müller 1993, Schubert et al. 1993, Tandeau de Marsac \& Houmard 1993, Bryant 1995). An increase of PE and PC within the PBSs, and/or changes in size and number of PS I reaction centres, may be the origin of this variability (Kawamura et al. 1979, Schubert \& Hagemann 1990, Müller et al. 1993, Reuter \& Müller 1993, Schubert et al. 1993, Tandeau de Marsac \& Houmard 1993, Bryant 1995). The accepted ratio of PBS:PS II is constant (Myers et al. 1980).

The variability of pigment composition affects the spectral characteristics of fluorescence emission of the red cyanobacterial photosynthetic apparatus (Appendix 1). The resulting status-dependent norm spectra can cause problems in the fluorometric spectral phytoplankton analysis (see Beutler et al. 2002b, 2003) and can lead to false chl estimations and algal group identification. Fig. 4 demonstrates that these problems can be overcome by the model described in Appendix 1, and that sufficient precision (deviations below 15\%) of specific biomass detection can be achieved.

In the cryptophytae Cryptomonas ovata, the light-induced acclimation processes and species-specific variability lead to differences in the PE:chl $a$ and chl $c_{2}$ :chl $a$ ratios (Fig. 2B,C). These changes in pigmentation lead to a change in the absorption cross-section of the PE and chl $c_{2}$ chl $a$ antennae. Their effect on fluorometric analysis (also reported by Sciandra et al. 2000) can be accounted for by the model in Appendix 2.

\section{Reliability of prediction of pigment contents in red cyanobacteria by the model in Appendix 1}

The assumption given in Eq. (A5) is that fluorescence yields and energy transfer rates among pigments in the red cyanobacterial photosynthetic apparatus are constant (analogous to blue cyanobacteria in Beutler et al. (2003). This simplifying assumption yields good pigment estimates (in Fig. 4) and results in only small pigment estimation deviations, as shown Fig. 9A. Even though this is an example of changes in $\Phi_{\mathrm{PC}, \mathrm{PS}}\left(\lambda_{\mathrm{ML}}\right)$ (Eq. A2b) (and thus, violates the assumption of Eq. A5), the effect on chl estimation is not significant. This seems to result from the fact that the apparent minor changes in the pigment estimation of PS II centres and chl in this figure might be compensated by changes in other pigment-topigment coupling sites.

Another interesting simplification of the real world by the model can be seen in the first 2 assumptions for phycobilin fluorescence represented by Eqs. (A7) \& (A9). This means that the fluorescence emissions at the detection wavelength 600, 620 and $650 \mathrm{~nm}$ result exclusively from phycobilin fluorescence emission. At first sight, this seems to be in contradiction to the results of Wyman (1992). This author explained deviations between PE content determined at $570 \mathrm{~nm}$ and chemically by means of variable coupling between PE and PC. Support for this hypothesis came from the observation that decoupling by glycerol caused a good coincidence between fluorometrically and chemically determined PE contents. The new approach, however, based on norm curves can distinguish between fluorescence coming from PE and PC. The results (Fig. 4) show that the assumption of constant coupling between PE and PC can be maintained. As an alternative explanation, also in line with results obtained here, the 
deviations observed by Wyman (1992) seem to result from fluorescence from $\mathrm{PC}$, which might have led to additional components in the measured fluorescence with varying magnitude.

Assumption 3 of the model in Appendix 1 is basically in accordance with the model for blue cyanobacteria in Beutler et al. (2003). This involves information about the energy distribution to PS II and PS I and their architecture. It is not surprising that total chl content in red cyanobacteria could also be estimated by 3 fit coefficients in Eq. (A15) (with the assumption that $c_{1, \text { chl }}$ is equal to zero) as the emission spectra at $685 \mathrm{~nm}$ show very low variation (below $5 \%$ ). This is probably due to the fact that the contribution of PS II reaction centres to the total chl content can be neglected.

\section{Prediction of pigment contents in Cryptophyta by the model in Appendix 2}

The distinguishing features of the model described in Appendix 2 for cryptophyta, in comparison with the model of red cyanobacteria in Appendix 1, is that PC is lacking as an intermediate to PS II (Fig. 3C), and most $\mathrm{chl}$ is associated with PS II in Cryptomonas spp. This rendered the model for pigment estimation in Appendix 2 much simpler than that for the cyanobacterial model. The model for cryptophytes also assumes constant fluorescence yields and energy transfer rates (Eq. A26). The validity of the 2 assumptions given by Eqs. (A27) \& (A28) holds within the scatter of Fig. 5. It is remarkable that Eq. (B11) is valid, although the chl $C_{2}$ : chl a ratio changes by a factor of 3 in Fig. 2B,C. This might be explained by a minor role of $\mathrm{chl} \mathrm{C}_{2}$ in the light-harvesting complex as compared to that of PE.

In order to estimate the pigments of red cyanobacteria and cryptophytes in the presence of other phytoplankton, the fit procedure of Appendix 3 was established. Within the fit procedure, the results of the growth experiments (stable norm spectra; Fig. 6) and the correction of norm spectra of the blue cyanobacteria and of other phytoplankton (see Beutler et al. 2003) were included. The mathematical fit procedure can utilize information from excitation and emission spectra for the determination of the pigments of 5 spectral algal groups by the use of the fluorescence models of Appendices 1 and 2, and the model for blue cyanobacteria of Beutler et al. (2003).

The fit procedure also takes spectral changes in the emission spectra into account. The additional use of the 600 and $620 \mathrm{~nm}$ detection wavelengths provides another characteristic feature for the differentiation of cryptophytes like Cryptomonas ovata containing $\mathrm{PE}_{566}$ and red cyanobacteria by virtue of the spectral differences in this region. This distinguishing feature is necessary, as the difference in the $685 \mathrm{~nm}$ excitation spectra (Fig. 6D) is not powerful, as there are spectral interferences with chl of the Chlorophyta and Chromophyta (unpubl. data).

The mathematical linear independence of the spectra and the correct operation of the fit are demonstrated in the dilution experiments of Fig. 5. Fig. 6 demonstrates the correct assessment of pigments by the mathematical fit during aging of a batch culture. This is a simulation of a situation that might occur during a natural phytoplankton bloom. It demonstrates that the model of Appendix 3 and the fit procedure are also valid for pigment systems that are degrading.

Changing light illumination over a time scale of minutes can induce photo-inhibition and energy state transitions of algal PSs. While effects of photo-inhibitory illumination on norm spectra under $685 \mathrm{~nm}$ emission were discussed in Beutler et al. (2002b), the effect of light intensities that induce state transitions and photo-inhibitory effects on pigment estimation by the use of the models in Appendices $1 \& 2$, and the mathematical fit procedure, can be seen in Fig. 9. It was found that the highest pigment estimation deviation, caused by state transitions and photo-inhibition together, was less than $15 \%$ in both organisms. Both organisms in Fig. 9 show the highest coupling to PS II over the range of growth light intensities. This is similar to the results of Campbell \& Öquist (1996), and was also found with blue cyanobacteria (Beutler et al. 2003).

The approach presented here should be adequate for most aquatic systems. In the case of cryptophytes or cyanobacteria containing different types of phycobilins, the detection wavelengths can be adapted to the emission wavelength. The fluorescence models can be used analogously for different organisms of the same group, as only the spectral characteristic might change and not the energy transfer and structural characteristics. A problem in natural waters might be the interference with yellow substances. This problem can be solved by a special norm spectrum for yellow substances for all 4 detection wavelengths in the same way that this was carried out for the single detection wavelength (Beutler et al. 2002a). As a next step, the method has to be tested with natural water samples and verified with reference methods like those employed in this study. Our first results obtained with natural samples were very promising (unpubl. results).

Another prospect for this method could be its application to picoplankton in the world's oceans. They often have a mixed LHC system consisting of chls and phycobiliproteins. A further improvement of the fluorometer system will become feasible if more sensitive CCD detectors become available for the measurements of more emission wavelengths for an enhanced spectral analysis of other phycobiliproteins. 
Acknowledgements. We thank Biophysical Biological Engineering Moldaenke for their help in setting-up the fluorometer, and Christian Moldaenke, H. Dau (FU-Berlin) and W. Lampert (MPI, Plön) for their scientific advice and support. This work was funded by the German BMBF (Project Number 03F0287A).

\section{LITERATURE CITED}

Baroli I, Melis A (1996) Photoinhibition and repair in Dunaliella salina acclimated to different growth irradiances. Planta 198:640-646

Becker A, Meister A, Wilhelm C (2002) Flow cytometric discrimination of various phycobilin-containing phytoplankton groups in a hypertrophic reservoir. Cytometry 48: $45-57$

Bennett A, Bogorad L (1973) Complementary chromatic adaptation in a filamentous blue-green-alga. J Cell Biol 58: 419-435

Beutler M, Wiltshire KH, Lüring C, Moldaenke C, Lohse D (2002a) Fluorometric depth-profiling of chlorophyll corrected for yellow substances. In: Arzul G (ed) Aquaculture environment and marine phytoplankton. IFREMER, Brest, p 231-238

Beutler M, Wiltshire KH, Meyer B, Moldaenke C, Lüring C, Meyerhöfer M, Hansen UP, Dau H (2002b) A fluorometric method for the differentation of algal populations in vivo and in situ. Photosynth Res 72:39-53

Beutler M, Wiltshire $\mathrm{KH}$, Arp M, Kruse J, Reineke C, Moldaenke C, Hansen UP (2003) A reduced model of the fluorescence from the cyanobacterial photosynthetic apparatus designed for the in situ detection of cyanobacteria. Biochim Biophys Acta Bioenergetics 1604:33-46

Bibby TS, Nield J, Barber J (2001) Iron deficiency induces the formation of an antenna ring around trimeric photosystem I in cyanobacteria. Nature 412:743-745

Biggins J, Bruce D (1989) Regulation of excitation-energy transfer in organisms containing phycobilins. Photosynth Res 20:1-34

Bryant DA (1995) The molecular biology of cyanobacteria. Kluwer Academic Publishers, Dordrecht

Campbell D, Öquist G (1996) Predicting light acclimation in cyanobacteria from nonphotochemical quenching of photosystem II fluorescence, which reflects state transitions in these organisms. Plant Physiol 111:1293-1298

Campbell D, Hurry V, Clarke AK, Gustafsson P, Öquist G (1998) Chlorophyll fluorescence analysis of cyanobacterial photosynthesis and acclimation. Microbiol Mol Biol Rev 62:667-683

Cowles TJ, Desiderio RA, Neuer S (1993) In situ characterization of phytoplankton from vertical profiles of fluorescence emission-spectra. Mar Biol 115:217-222

Dau H (1994a) Molecular mechanisms and quantitative models of variable photosystem-II fluorescence. Photochem Photobiol 60:1-23

Dau H (1994b) Short-term adaptation of plants to changing light intensities and its relation to photosystem-II photochemistry and fluorescence emission. J Photochem Photobiol B 26:3-27

Desiderio RA, Moore C, Lantz C, Cowles TJ (1997) Multiple excitation fluorometer for in situ oceanographic applications. Appl Opt 36:1289-1296

Falkowski PG, Raven JA (1997) Aquatic photosynthesis. Blackwell Science, Oxford

Gerhardt V, Bodemer U (1998) Delayed fluorescence excitation spectroscopy: a method for automatic determination of phytoplankton composition of freshwaters and sediments interstitial) and of algal composition of benthos. Limnologica 28:313-323

Govindjee, Knox RS, Amesz J (1996) Photosynthetic unit: antenna and reaction centers. Photosynth Res 48:1-2

Guillard RRL, Lorenzen CJ (1972) Yellow-green algae with chlorophyllide $C$. J Phycol 8:10-14

Harnischfeger G, Herold B (1981) Aspects of energy-transfer between phycobilins and chlorophyll in Chroomonas spec (Cryptophycea). Ber Deutschen Bot Gesell 94:65-73

Holzwarth AR (1991) Structure-function-relationships and energy-transfer in phycobiliprotein antennae. Physiol Plant 83:518-528

Kawamura M, Mimuro M, Fujita Y (1979) Quantitative relationship between 2 reaction centers in the photosynthetic system of blue-green-algae. Plant Cell Physiol 20:697-705

Kolbowski J, Schreiber U (1995) Computer-controlled phytoplankton analyzer based on a 4 -wavelength PAM Chl fluorometer. In: Mathis P (ed) From light to biosphere. Kluwer Academic Publishers, Dordrecht, p 825-828

Lampert W, Sommer U (1997) Limnoecology: the ecology of lakes and streams. Oxford University Press, New York

Leboulanger C, Dorigo U, Jacquet S, Le Berre B, Paolini G, Humbert $J$ (2002) Application of a submersible spectrofluorometer for rapid monitoring of freshwater cyanobacterial blooms: a case study. Aquat Microb Ecol 30

Lee T, Tsuzuki M, Takeuchi T, Yokoyama K, Karube I (1994) In-vivo fluorometric method for early detection of cyanobacterial waterblooms. J Appl Phycol 6:489-495

Lichtle C, Jupin H, Duval JC (1980) Energy transfers from photosystem-2 to photosystem-1 in CryptomonasRufescens (Cryptophyceae). Biochim Biophys Acta 591: 104-112

Lichtle C, McKay RML, Gibbs SP (1992) Immunogold localization of photosystem-I and photosystem-II light-harvesting complexes in cryptomonad thylakoids. Biol Cell 74: $187-194$

Maccoll R, Berns DS (1978) Energy-transfer studies on cryptomonad biliproteins. Photochem Photobiol 27:343-349

MacColl R, Guard-Friar D (1987) Phycobiliproteins. CRC Press, Boca Raton, FL

McKay RML, Lichtle C, Gibbs SP (1992) Immunocytochemical characterization of the intrapyrenoid thylakoids of cryptomonads. J Phycol 28:64-68

Millie DF, Schofield OME, Kirkpatrick GJ, Johnsen G, Evens TJ (2002) Using absorbance and fluorescence spectra to discriminate microalgae. Eur J Phycol 37:313-322

Müller C, Reuter W, Wehrmeyer W, Dau H, Senger H (1993) Adaptation of the photosynthetic apparatus of AnacystisNidulans to irradiance and $\mathrm{CO}_{2}$-concentration. Bot Acta 106:480-487

Myers J, Graham JR, Wang RT (1980) Spontaneous pigment mutants of Anacystis-Nidulans selected by growth under far-red light. Arch Microbiol 124:143-148

Nelder JA, Mead R (1965) A simplex-method for function minimization. Comp J 7:308-313

Reuter W, Müller C (1993) Adaptation of the photosynthetic apparatus of cyanobacteria to light and $\mathrm{CO}_{2}$. J Photochem Photobiol B 21:3-27

Riethman HC, Sherman LA (1988) Purification and characterization of an iron stress-induced chlorophyll-protein from the cyanobacterium Anacystis-Nidulans R2. Biochim Biophys Acta 935:141-151

Rippka R, Herdman M (1992) Pasteur culture collection of cyanobacterial strains in axenic culture. In: Catalogue of strains, Vol 1. Institut Pasteur, Paris

Rowan KS (1989) Photosynthetic pigments of algae. Cam- 
bridge University Press, New York

Schubert H, Hagemann M (1990) Salt effects on 77k fluorescence and photosynthesis in the cyanobacterium Synechocystis sp Pcc-6803. FEMS Microbiol Lett 71:169-172

Schubert H, Fulda S, Hagemann M (1993) Effects of adaptation to different salt concentrations on photosynthesis and pigmentation of the cyanobacterium Synechocystis sp. Pcc-6803. J Plant Physiol 142:291-295

Sciandra A, Lazzara L, Claustre H, Babin M (2000) Responses of growth rate, pigment composition and optical properties of Cryptomonas sp. to light and nitrogen stresses. Mar Ecol Prog Ser 201:107-120

Seppala J, Balode M (1998) The use of spectral fluorescence methods to detect changes in the phytoplankton community. Hydrobiologia 363:207-217

Straus N (1994) Iron deprivation:physiology and gene regulation. In: Bryant D (ed) The molecular biology of cyanobacteria. Kluwer Academic Press, Dordrecht, p 731-750

Tandeau de Marsac NT, Houmard J (1993) Adaptation of cyanobacteria to environmental stimuli-new steps towards molecular mechanisms. FEMS Microbiol Rev 104: 119-189

van den Hoek C, Mann DG, Jahns HM (1995) Algae: an introduction to phycology. Cambridge University Press, New York

van Grondelle R, Dekker JP, Gillbro T, Sundstrom V (1994) Energy-transfer and trapping in photosynthesis. Biochim Biophys Acta Bioenergetics 1187:1-65 van Kooten O, Snel JFH (1990) The use of chlorophyll fluorescence nomenclature in plant stress physiology. Photosynth Res 25:147-150

van Thor JJ, Mullineaux CW, Matthijs HCP, Hellingwerf KJ (1998) Light harvesting and state transitions in cyanobacteria. Bot Acta 111:430-443

Williams WP, Allen JF (1987) State-1/State-2 changes in higher-plants and algae. Photosynth Res 13:19-45

Wiltshire $\mathrm{KH}$, Harsdorf S, Smidt B, Blocker G, Reuter R, Schroeder F (1998) The determination of algal biomass (as chlorophyll) in suspended matter from the Elbe estuary and the German Bight: a comparison of high-performance liquid chromatography, delayed fluorescence and prompt fluorescence methods. J Exp Mar Biol Ecol 222:113-131

Wyman M (1992) An in vivo method for the estimation of phycoerythrin concentrations in marine cyanobacteria (Synechococcus spp). Limnol Oceanogr 37:1300-1306

Yentsch CS, Phinney DA (1985) Spectral fluorescence-an ataxonomic tool for studying the structure of phytoplankton populations. J Plankton Res 7:617-632

Yentsch CS, Yentsch CM (1979) Fluorescence spectral signatures - characterization of phytoplankton populations by the use of excitation and emission-spectra. J Mar Res 37: 471-483

Zhou JH, Gasparich GE, Stirewalt VL, Delorimier R, Bryant DA (1992) The Cpce and Cpcf genes of Synechococcus sp. Pcc-7002 - construction and phenotypic characterization of interposon mutants. J Biol Chem 267:16138-16145

Appendix 1. Fluorescence model of phycoerythrin-containing cyanobacteria

The flux of energy between the pigment systems of red cyanobacteria and the resulting generation of fluorescence is illustrated in Fig. 3A. The implications for fluorometric chl determination of phycoerythrin (PE) as an additional pigment in cyanobacteria are described in mathematical terms below. The derivations are done under the assumption that the algal suspensions are optically sufficiently thin. Otherwise, additional terms would be required to correct for mutual shading of algae and for fluorescence re-absorption. The mathematical description is similar to that of Beutler et al. (2003) for cyanobacteria containing only phycocyanin (PC) and allophycocyanin.

\section{Fluorescence of pigments}

The fluorescence intensity of the pigments are:

$$
F_{\mathrm{P}}\left(\lambda_{\mathrm{ML}}, \lambda_{\mathrm{em}}\right)=C_{\mathrm{instr}, \mathrm{P}} I_{\mathrm{ML}}\left(\lambda_{\mathrm{ML}}\right) N_{\mathrm{P}} A_{\mathrm{eff}, \mathrm{P}}\left(\lambda_{\mathrm{ML}}\right) \Phi_{\mathrm{F}, \mathrm{P}}
$$

where P represents PE, PC, PS II or PSI; $F=$ fluorescence; $C_{\text {instr, }}=$ calibrating constant of the instrument; $I_{\mathrm{ML}}\left(\lambda_{\mathrm{ML}}\right)=$ light intensity of the measuring light of wavelength $\lambda_{\mathrm{ML}}$ (in $\mu \mathrm{mol}$ photons $\mathrm{m}^{-2} \mathrm{~s}^{-1}$ ) $N_{\mathrm{P}}=$ number of pigment molecules in the sample volume; $\Phi_{F_{1} \text { P }}=$ fluorescence yield of pigment. $\Phi_{F, \text { PS II }}$ and its variability are discussed by Dau (1994a,b) and Govindjee et al. (1996). The effective absorption cross-section $\left(\mathrm{m}^{2}\right)$ per molecule $A_{\mathrm{eff}, \mathrm{P}}\left(\lambda_{\mathrm{ML}}\right)$ can be more complex due to energy transfer between pigments. $A_{\text {eff,PE }}$ depends on PE only; thus,

$$
A_{\text {eff,PE}}\left(\lambda_{\mathrm{ML}}\right)=A_{\mathrm{PE}}\left(\lambda_{\mathrm{ML}}\right)
$$

In the case of the other cross sections, 2 pigments are always involved:

$$
\begin{aligned}
A_{\mathrm{eff}, \mathrm{PC}}\left(\lambda_{\mathrm{ML}}\right) & =\Phi_{\mathrm{PE}, \mathrm{PC}}\left(\lambda_{\mathrm{ML}}\right) N_{\mathrm{PE}} A_{\mathrm{PE}}\left(\lambda_{\mathrm{ML}}\right)+N_{\mathrm{PC}} A_{\mathrm{PC}}\left(\lambda_{\mathrm{ML}}\right) \\
A_{\text {eff,PS II }}\left(\lambda_{\mathrm{ML}}\right) & =\Phi_{\mathrm{PC}, \mathrm{PS} \text { II }}\left(\lambda_{\mathrm{ML}}\right) A_{\text {peri,PS II }}\left(\lambda_{\mathrm{ML}}\right)+A_{\text {corePS II }}\left(\lambda_{\mathrm{ML}}\right) \\
A_{\mathrm{eff}, \mathrm{PSI} I}\left(\lambda_{\mathrm{ML}}\right) & =\Phi_{\mathrm{PC}, \mathrm{PSI}}\left(\lambda_{\mathrm{ML}}\right) A_{\text {peri,PS I }}\left(\lambda_{\mathrm{ML}}\right)+A_{\text {core,PSI }}\left(\lambda_{\mathrm{ML}}\right)
\end{aligned}
$$

where $\Phi_{\mathrm{P}, \mathrm{Q}}$ describes the energy transfer yield from pigment $\mathrm{P}$ to pigment $\mathrm{Q}_{i} A_{\text {peri,PS II }}$ and $A_{\text {corePS II }}$ are the effective absorption cross-section of the peripheral and the core PS II antenna, respectively.

In phycobilisome (PBS)-containing algae the peripheral antenna of photosystems (PS) I and PS II is the PBS. Thus, the peripheral antenna of PS II and PS I are identical, and the cross section in cyanobacteria is:

$$
A_{\text {peri,PSI }}\left(\lambda_{\mathrm{ML}}\right)=A_{\text {peri,PS II }}\left(\lambda_{\mathrm{ML}}\right)=A_{\text {eff,PC }}\left(\lambda_{\mathrm{ML}}\right)=\Phi_{\mathrm{PE}, \mathrm{PC}}\left(\lambda_{\mathrm{ML}}\right) N_{\mathrm{PE}} A_{\mathrm{PE}}\left(\lambda_{\mathrm{ML}}\right)+A_{\mathrm{PC}}\left(\lambda_{\mathrm{ML}}\right)
$$


Appendix 1 (continued)

\section{Total fluorescence in PBS-containing algae}

The total fluorescence ( $F$ without pigment index) is given as a sum of the fluorescence intensities for all 4 indices of Eq. (A1):

$$
F\left(\lambda_{\mathrm{ML}}, \lambda_{\mathrm{em}}\right)=F_{\mathrm{PE}}\left(\lambda_{\mathrm{ML}}, \lambda_{\mathrm{em}}\right)+F_{\mathrm{PC}}\left(\lambda_{\mathrm{ML}}, \lambda_{\mathrm{em}}\right)+F_{\mathrm{PS} \mathrm{II}}\left(\lambda_{\mathrm{ML}}, \lambda_{\mathrm{em}}\right)+F_{\mathrm{PSI}}\left(\lambda_{\mathrm{ML}}, \lambda_{\mathrm{em}}\right)
$$

The instrument has 7 excitation wavelengths $\left(\lambda_{\mathrm{ML}}\right)$ and 4 emission wavelengths $\left(\lambda_{\text {em }}\right)$. Thus Eq. (A4) represents a set of 28 equations. Introducing Eqs. (A1) to (A3) converts Eq. (A4) to:

$$
\begin{aligned}
F\left(\lambda_{\mathrm{ML}}, \lambda_{\mathrm{em}}\right)= & {\left[k_{1, \lambda \mathrm{ML}, \lambda \mathrm{em}} N_{\mathrm{PE}}\right]+\left[k_{2, \lambda \mathrm{ML}, \lambda \mathrm{em}} \mathrm{N}_{\mathrm{PE}}+k_{3, \lambda \mathrm{ML}, \lambda \mathrm{em}} N_{\mathrm{PC}}\right]+\left[k_{4, \lambda \mathrm{ML}, \lambda \mathrm{em}} \mathrm{N}_{\mathrm{PE}}+k_{5, \lambda \mathrm{ML}, \lambda \mathrm{em}} N_{\mathrm{PC}}+\mathrm{k}_{6, \lambda \mathrm{ML}, \lambda \mathrm{em}} N_{\mathrm{PS} \text { II }}\right]+} \\
& {\left[k_{7, \lambda \mathrm{ML}, \lambda \mathrm{em}} N_{\mathrm{PE}}+k_{8, \lambda \mathrm{ML}, \lambda \mathrm{em}} N_{\mathrm{PC}}+\mathrm{k}_{9, \lambda \mathrm{ML}, \lambda \mathrm{em}} N_{\mathrm{PS} \mathrm{I}}\right] }
\end{aligned}
$$

with the gross rate constants $k_{\mathrm{i}, \lambda \mathrm{ML}, \lambda \mathrm{em}}$ for $\mathrm{i}=1$ to 9 (rate constants because they are fluorescence flux per pigment number). In order to solve the set of Eq. (A4), it is necessary that the gross rate constants of Eq. (A6) are constant, i.e. independent of light intensity and growth conditions. This leads to the first assumption.

First assumption: The gross rate constants $k_{\mathrm{i}, \lambda \mathrm{ML}, \lambda \mathrm{em}}$ remain constant. This assumption needs further comment, and in the 'Discussion' its validity is considered with the result that it is verified by reported results from both other workers and the experimental findings (compare Beutler et al. 2003). The determination of the pigment numbers $N_{\mathrm{p}}$ and the 9 gross rate constants from 28 equations (A4) needs a lot of computer time that may be not available in on-line applications. As 13 unknown parameters need only 13 equations, the number of equations is reduced by the next assumptions.

Second assumption: A simple solution of Eq. (A4) is obtained under the assumption that fluorescence emission at 600 and $650 \mathrm{~nm}$ induced by excitation with $570 \mathrm{~nm}$ light originates mainly from PE and PC molecules. Presenting this assumption separately for emission at 600 and $650 \mathrm{~nm}$ leads to:

$$
\begin{aligned}
& F_{570,600}=F_{\mathrm{PE}, 570,600}+F_{\mathrm{PC}, 570,600} \text { with } F_{\mathrm{PSII}, 570,600} \approx F_{\mathrm{PSI}, 570,600} \approx 0 \\
& F_{570,650}=F_{\mathrm{PE}, 570,650}+F_{\mathrm{PC}, 570,650} \text { with } F_{\mathrm{PS} \text { II, } 570,650} \approx F_{\mathrm{PSI}, 570,650} \approx 0
\end{aligned}
$$

Eq. (A6) leads to the omission of $N_{\text {PS II }}$ and $N_{\text {PSI }}$ in the equations for $F_{570,600}$ and $F_{570,650}$ in the A4 set. The solution of the resulting system of 2 equations leads to a simple relationship between $N_{\mathrm{PE}}$ and $N_{\mathrm{PC}}$ to the 2 signals $F_{570,650}$ and $F_{570,600}$.

$$
N_{\mathrm{PE}}=\mathrm{C}_{1, \mathrm{PE}} F_{570,650}+C_{2, \mathrm{PE}} F_{570,600}
$$

The $C_{\mathrm{i}, \mathrm{PE}}$ have to be determined by calibration experiments (Fig. 4A,B). The relationship to the gross rate constants (Eq. A5) is obtained from the solution of Eq. (A6):

and

$$
\begin{array}{r}
c_{1, \mathrm{PE}}=-k_{3,570,600} k_{3,570,650}{ }^{-1}\left(k_{1,570,600}+k_{2,570,600}-k_{1,570,650} k_{3,570,650}{ }^{-1} k_{3,570,600}-k_{2,570,650} k_{3,570,600} k_{3,570,650}{ }^{-1}\right) \\
c_{2, \mathrm{PE}}=\left(k_{1,570,600}+k_{2,570,600}-k_{1,570,650} k_{3,570,650}{ }^{-1} k_{3,570,600}-k_{2,570,650} k_{3,570,600} k_{3,570,650}\right)^{-1}
\end{array}
$$

$$
N_{\mathrm{PC}}=C_{1, \mathrm{PC}} F_{570,650+C_{2, \mathrm{PC}} F_{570,600}}
$$

$$
\left.\left.c_{1, \mathrm{PC}}=\left(k_{1,570,600}+k_{2,570,600}\right)\left(-k_{3,570,650}\right] k_{1,570,650}+k_{2,570,650}\right]^{-1}-k_{3,570,600}\left[k_{1,570,600}+k_{2,570,600}\right]^{-1}\right)^{-1}
$$$$
c_{2, \mathrm{PC}}=\left(k_{1,570,650}+k_{2,570,650}\right)\left(-k_{3,570,650}\left[k_{1,570,650}+k_{2,570,650}\right]^{-1}-\mathrm{k}_{3,570,600}\left[\mathrm{k}_{1,570,600}+\mathrm{k}_{2,570,600}\right]^{-1}\right)^{-1}
$$

Since $N_{\mathrm{PE}}$ and $N_{\mathrm{PC}}$ can be replaced by $F_{570,650}$ and $F_{570,600}$ in Eq. (A5), only 2 unknown variables remain in Eq. (A5). Thus, 2 adequate equations, i.e. $F\left(\lambda_{1 \mathrm{ML}}, \lambda_{\text {lem }}\right)$ and $F\left(\lambda_{2 \mathrm{ML}}, \lambda_{2 \mathrm{em}}\right)$, out of Eq. (A5) have to be selected to calculate $N_{\mathrm{PS} \text { II }}$ and $N_{\mathrm{PS} \text { I. }}$. This leads to the following solutions:

$$
\begin{aligned}
N_{\mathrm{PS} \mathrm{II}} & =c_{1, \mathrm{PS} \text { II }} F\left(\lambda_{1 \mathrm{ML}}, \lambda_{1 \mathrm{em}}\right)+c_{2, \mathrm{PS} I I} F\left(\lambda_{2 \mathrm{ML}}, \lambda_{2 \mathrm{em}}\right)+c_{3, \mathrm{PS} \mathrm{II}} F_{570,650}+c_{4, \mathrm{PS} \mathrm{II}} F_{570,600} \\
N_{\mathrm{PSI}} & =c_{1, \mathrm{PSI}} F\left(\lambda_{1 \mathrm{ML},} \lambda_{1 \mathrm{em}}\right)+c_{2, \mathrm{PSI}} F\left(\lambda_{2 \mathrm{ML}}, \lambda_{2 \mathrm{em}}\right)+c_{3, \mathrm{PSI}} F_{570,650}+c_{4, \mathrm{PSI}} F_{570,600}
\end{aligned}
$$

$F\left(\lambda_{1 \mathrm{ML}}, \lambda_{1 \mathrm{em}}\right)$ and $F\left(\lambda_{2 \mathrm{ML}}, \lambda_{2 \mathrm{em}}\right)$ were selected using the findings of Beutler et al. (2003), where it was found that PS II fluorescence was mainly represented at a wavelength of maximal phycobilin absorption (570 $\mathrm{nm}$ in case of PE) and $685 \mathrm{~nm}$ emission. PS I gives the strongest signal under chl absorption $(470 \mathrm{~nm})$ and $685 \mathrm{~nm}$ emission. This leads to the selection of:

$$
\begin{aligned}
& F\left(\lambda_{1 \mathrm{ML}}, \lambda_{1 \mathrm{em}}\right)=F_{570,685} \\
& F\left(\lambda_{2 \mathrm{ML}}, \lambda_{2 \mathrm{em}}\right)=F_{470,685}
\end{aligned}
$$

The parameters $C_{\mathrm{i}, \mathrm{PS} I \mathrm{II}}$ and $C_{\mathrm{i}, \mathrm{PSI}}$ of Eq. (A11) have to be determined by calibration experiments like those in Fig. 4 . Their relationships to the gross rate constants (Eq. A5) are obtained from a solution of the 2 selected equations (A12 \& A13). The substitution of $N_{\mathrm{PE}}$ and $N_{\mathrm{PC}}$ by Eqs. (A7) \& (A9), similar to Beutler et al. (2003), is no longer presented here in detail.

Third assumption: The sum of chl in PS II and PS I reaction centres is constant, i.e. independent of environmental conditions. If some of the reactions centres have a variable amount of associated chl (e.g. during a repair cycle, Baroli \& Melis 1996), then the analysis presents an average amount of chl per PS II or PS I reaction centre.

In other words, in the sum:

$$
\text { Conc }_{\mathrm{CHL}}=\mathrm{p}_{1, \mathrm{chl}} N_{\mathrm{PSI}}+\mathrm{p}_{2, \text { chl }} N_{\mathrm{PS} \text { II }}
$$

$\mathrm{p}_{1, \text { chl }}, \mathrm{p}_{2, \mathrm{chl}}$ are assumed to be constants. Adding Eq. (A11a) to Eq. (A11b) yields the total chl concentration:

$$
\text { conc }_{\text {chl }}=C_{1, \mathrm{chl}} F_{570,685}-C_{2, \mathrm{chl}} F_{470,685}-C_{3, \mathrm{chl}} F_{570,650}-C_{4, \mathrm{chl}} F_{570,600}
$$

with the coefficients given by the parameters of Eqs. (A11a) \& (A11b):

$$
\begin{array}{ll}
C_{1, \mathrm{chl}}=\left(c_{1, \mathrm{PS} \text { II }}+C_{1, \mathrm{PSI}}\right), & c_{2, \mathrm{chl}}=-\left(c_{2, \mathrm{PS} \text { II }}+C_{2, \mathrm{PSI}}\right) \\
C_{3, \mathrm{chl}}=-\left(c_{3, \mathrm{PS} \text { II }}+C_{3, \mathrm{PSI}}\right), & C_{4, \mathrm{chl}}=-\left(c_{4, \mathrm{PS} \text { II }}+C_{4, \mathrm{PSI}}\right)
\end{array}
$$


Appendix 2. Energy distribution model of cryptophytes

The flux of energy between the pigment systems of cryptophytes and the generation of fluorescence is illustrated in Fig. 3B. The derivations were done under the assumption that the algal suspensions are optically sufficiently thin. In cryptophytes, the assumption of rapid exciton equilibrium (REE) involving all antenna pigments is not valid like in Chlorophyta. This is similar to the situation in cyanobacteria. Phycobilins in cryptophytes are localised in the thylakoid lumen. They can serve energy to the chl $c_{2}$-chl a antenna. There is only downhill flux from phycoerythrin (PE) to the chl $c_{2}$-chl $a$ antenna, and thus REE does not hold. Within chl $C_{2}$-chl a antenna, REE can be assumed.

The simple model of energy transfer processes in Fig. 3B leads to a mathematical description that can be used as a basis for a mathematical fit procedure for the estimation of the pigments phycoerythrin (PE) and chl in cryptophytes.

Fluorescence of PE in cryptophyta

The fluorescence intensity of PE is:

$$
F_{\mathrm{PE}}\left(\lambda_{\mathrm{ML}}, \lambda_{\mathrm{em}}\right)=\mathrm{C}_{\mathrm{instr}, \mathrm{PE}} N_{\mathrm{PE}} I_{\mathrm{ML}}\left(\lambda_{\mathrm{ML}}\right) A_{\mathrm{PE}}\left(\lambda_{\mathrm{ML}}\right) \Phi_{F_{1} \mathrm{PE}}
$$

with $c_{\text {instr,PE }}=$ a calibration factor of the set-up, $N_{\mathrm{PE}}=$ number of PE molecules in the sample volume; $A_{\mathrm{PE}}\left(\lambda_{\mathrm{ML}}\right)=\mathrm{PE}$ molecule absorption cross-section $\left(\mathrm{m}^{2}\right) ; I_{\mathrm{ML}}=$ intensity of the measuring light (in $\mu \mathrm{mol}$ photons $\left.\mathrm{m}^{-2} \mathrm{~s}^{-1}\right) ; \lambda_{\mathrm{em}}=$ fluorescence emission wavelength, $\lambda_{\mathrm{ML}}=$ wavelength of measuring light; $\Phi_{F, \mathrm{PE}}=$ fluorescence yield of PE.

Fluorescence of PS II in cryptophytes

For the fluorescence emission of photosystem (PS) II, the model in Fig. 3B results in:

with

$$
\begin{gathered}
F_{\mathrm{PS} \mathrm{II}}\left(\lambda_{\mathrm{ML}}, \lambda_{\mathrm{em}}\right)=c_{\mathrm{instr}, \mathrm{PS} \text { II }} N_{\mathrm{PS} \mathrm{II}} I_{\mathrm{ML}}\left(\lambda_{\mathrm{ML}}\right) A_{\text {eff, PS II }}\left(\lambda_{\mathrm{ML}}\right) \Phi_{F, \mathrm{PS} \text { II }} \\
A_{\text {eff,PS II }}\left(\lambda_{\mathrm{ML}}\right)=\Phi_{\mathrm{PE}, \mathrm{PS} \text { II }}\left(\lambda_{\mathrm{ML}}\right) A_{\text {peri,PS II }}\left(\lambda_{\mathrm{ML}}\right)+A_{\text {corePS II }}\left(\lambda_{\mathrm{ML}}\right)
\end{gathered}
$$

with $C_{\text {instr }, \text { PS II }}, N_{\mathrm{PS} \mathrm{II}}, A_{\mathrm{PS} \mathrm{II}}\left(\lambda_{\mathrm{ML}}\right), I_{\mathrm{ML}}$ defined similarly as in Eq. (A18). $A_{\text {peri,PS II }}\left(\lambda_{\mathrm{ML}}\right)$ and $A_{\text {core }}\left(\lambda_{\mathrm{ML}}\right)$ are the individual absorption cross-sections of the peripheral (PE) and the core antenna. In the case of the Cryptophyta core antenna, $A_{\text {peri,PS II }}\left(\lambda_{\mathrm{ML}}\right)$ denotes

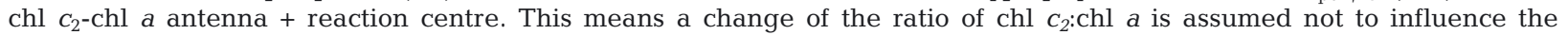
$A_{\text {peri,PS II }}\left(\lambda_{\mathrm{ML}}\right)$ very strongly. The parameter $A_{\mathrm{eff}, \mathrm{PS} \mathrm{II}}\left(\lambda_{\mathrm{ML}}\right)$ represents an effective absorption cross-section of the PS II (core complex and peripheral antenna); $\Phi_{F, \text { PSII }}$ and its variability has been previously discussed (e.g. Dau 1994a,b, Govindjee et al. 1996). This denotes the wavelength-independent fluorescence yield measurable for direct (absorption by a pigment of the core antenna) or indirect excitation (energy transfer from the peripheral antenna to the core antenna) of the PS II-core antenna. $\Phi_{\mathrm{PE}, \mathrm{PS} \text { II }}$ is the energy transfer yield from the peripheral antenna (PE) to the PS I-core antenna.

In order to estimate the number of PE molecules, the number of reaction centres and the total amount of chl $a$ in a sample volume from measured fluorescence spectra, 2 assumptions were made (tested and checked in the results section above, Fig. 5).

\section{Fluorescence of PS I in cryptophytes}

First assumption: As most chl in Cryptophyta resides within the peripheral antenna of PS II, chl fluorescence emission of ca. $685 \mathrm{~nm}$ from PS I is assumed to be negligible. The overall fluorescence for a single excitation and emission wavelength (in a wavelength range between 600 and $685 \mathrm{~nm}$ ) is given as a sum of the fluorescence of PE and PS II:

$$
F_{\text {tot }}\left(\lambda_{\mathrm{ML}}, \lambda_{\text {em }}\right)=F_{\mathrm{PE}}\left(\lambda_{\mathrm{ML}}, \lambda_{\mathrm{em}}\right)+F_{\mathrm{PS} \mathrm{II}}\left(\lambda_{\mathrm{ML}}, \lambda_{\mathrm{em}}\right)
$$

By substituting $F_{\mathrm{PE}}\left(\lambda_{\mathrm{ML}}, \lambda_{\mathrm{em}}\right), F_{\mathrm{PS} \mathrm{II}}\left(\lambda_{\mathrm{ML}}, \lambda_{\mathrm{em}}\right)$ as given in Eqs. (A18) to (A20), we arrive at:

$$
\begin{aligned}
F_{\text {tot }}\left(\lambda_{\mathrm{ML}}, \lambda_{\mathrm{em}}\right)= & {\left[N_{\mathrm{PE}} C_{\mathrm{instr}, \mathrm{PE}} I_{\mathrm{ML}}\left(\lambda_{\mathrm{ML}}\right) A_{\mathrm{PE}}\left(\lambda_{\mathrm{ML}}\right) \Phi_{F, \mathrm{PE}}\right]+\left[N_{\mathrm{PS} \mathrm{II}} C_{\text {instr }, \mathrm{PS} \mathrm{II}} \mathrm{I}_{\mathrm{ML}}\left(\lambda_{\mathrm{ML}}\right)\right]\left\{\left[\Phi_{\mathrm{PE}, \mathrm{PS} \mathrm{II}}\left(\lambda_{\mathrm{ML}}\right) A_{\text {peri,PS II }}\left(\lambda_{\mathrm{ML}}\right)\right]+\right.} \\
& {\left.\left.\left[A_{\text {core, } \mathrm{PS} \mathrm{II}}\left(\lambda_{\mathrm{ML}}\right) \Phi_{F, \mathrm{PS} \text { II }}\right]\right\}\right] }
\end{aligned}
$$

In cryptophytes, the absorption cross-section of the peripheral antenna of PS II is equal to the absorption cross section of the PE. The absorption cross-section is proportional to the PE content in the antenna, assuming that:

$$
\begin{gathered}
A_{\text {peri,PS II }}\left(\lambda_{\mathrm{ML}}\right)=c_{1}\left(\lambda_{\mathrm{ML}}\right) N_{\mathrm{PE}} / N_{\mathrm{PS} \mathrm{II}} \\
\text { with } c_{1}\left(\lambda_{\mathrm{ML}}\right)=\text { constant, and } c_{2}\left(\lambda_{\mathrm{ML}}\right)=\text { constant leads to: } \\
F_{\mathrm{tot}}\left(\lambda_{\mathrm{ML}}, \lambda_{\mathrm{em}}\right)=I_{\mathrm{ML}}\left(\lambda_{\mathrm{ML}}\right)\left[\left(N_{\mathrm{PE}} c_{\mathrm{instr}, \mathrm{PE}} A_{\mathrm{PE}}\left(\lambda_{\mathrm{ML}}\right) \Phi_{F, \mathrm{PE}}\right)\right]+ \\
\left\{c_{\text {instr }, \mathrm{PS} \mathrm{II}}\left[c_{1}\left(\lambda_{\mathrm{ML}}\right) \Phi_{\mathrm{PE}, \mathrm{PS} \mathrm{II}}\left(\lambda_{\mathrm{ML}}\right) N_{\mathrm{PE}} A_{\mathrm{PE}}\left(\lambda_{\mathrm{ML}}\right)\right]+\left[N_{\mathrm{PS} \text { II }} A_{\mathrm{core}, \mathrm{PS} \text { II }}\left(\lambda_{\mathrm{ML}}\right)\right] \Phi_{F, \mathrm{PS} \mathrm{II}}\right\}
\end{gathered}
$$

Introducing the gross rate constants $k_{\mathrm{i}, \lambda \mathrm{ML}, \lambda \mathrm{em}}$ into Eq. (A25) leads to Eq. (A26) for the overall fluorescence:

$$
F_{\text {tot }}\left(\lambda_{\mathrm{ML}}, \lambda_{\mathrm{em}}\right)=N_{\mathrm{PE}}\left(k_{1, \lambda \mathrm{ML}, \lambda \mathrm{em}}+k_{2, \lambda \mathrm{ML}, \lambda \mathrm{em}}\right)+\left(N_{\mathrm{PS} \mathrm{II}} k_{3, \lambda \mathrm{ML}, \lambda \mathrm{em}}\right)
$$

Second assumption: The number of PE molecules is proportional to the fluorescence intensity at an excitation wavelength of the $570 \mathrm{~nm}$ LED and emission at the $620 \mathrm{~nm}$ channel. This means that [ $\left.c_{\mathrm{instr}, \mathrm{PE}} I_{\mathrm{ML}}\left(\lambda_{\mathrm{ML}}\right) A_{\mathrm{PE}}\left(\lambda_{\mathrm{ML}}\right) \Phi_{\mathrm{F}, \mathrm{PE}}\right]$ is set as constant in Eq. (A18). No interference with PS II and PS I fluorescence is expected.

$$
F_{570,620} k_{1,620^{-1}}=N_{\mathrm{PE}}
$$

According to the first assumption, the chl a associated with PS I can be neglected in the total chl estimation by fluorescence.

$$
\begin{gathered}
\mathrm{chl} \sim N_{\mathrm{PS} \mathrm{II}}=c_{1, \mathrm{PS} \mathrm{II}} F_{\text {tot }}\left(\lambda_{1 \mathrm{ML},} \lambda_{1 \mathrm{em}}\right)-c_{2, \mathrm{PS} \mathrm{II}} F_{570,620} \\
F_{\text {tot }}\left(\lambda_{1 \mathrm{ML}}, \lambda_{1 \mathrm{em}}\right)=F_{570,685} \\
c_{1, \mathrm{PS} \text { II }}=k_{3, \lambda \mathrm{ML}, \lambda \mathrm{em}^{-1}} \\
c_{2, \mathrm{PS} \mathrm{II}}=k_{1,620}\left(k_{1, \lambda \mathrm{ML}, \lambda \mathrm{em}}+k_{2, \lambda \mathrm{ML}, \lambda \mathrm{em}}\right) k_{3, \lambda \mathrm{ML}, \lambda \mathrm{em}^{-1}}
\end{gathered}
$$


Appendix 3. Mathematical fit for cyanobacterial spectra with several excitation and detection wavelengths using variable cyanobacterial norm spectra

\begin{abstract}
In order to calculate the fluorescence parameters for the models in Appendices $1 \& 2$, a fit procedure was developed that is capable of accounting for fluorescence emission of other spectral algal groups, correcting for variations of the cyanobacterial norm spectra, evaluating the fit for 4 emission channels and providing rapid convergence for implementation in on-line analysis. This was achieved by extending the fit routine of Beutler et al. (2003) to 4 emission wavelengths using the experiments in the 'Results' section.

The variability of the norm spectra of the blue cyanobacteria requires a non-linear fit routine.

Thus, the fit routine was split into 2 parts: the core fit and the main fit. The core was a sub-routine of the main fit. The main fit selected one spectrum out of the set of 40 norm spectra of the blue cyanobacteria and handed it over to the core fit. The core fit always believes that this special blue norm spectrum is the true one, and calculates the pigment concentrations by linear regression. However, the core fit was run under the supervision of the main fit. The main fit provided the core fit with a sequence of different norm spectra of the blue cyanobacteria, selected by means of a simplex algorithm (Nelder \& Mead 1965). During these repetitive runs of the core fit, the main fit inspected the error sums delivered by the core fit. Finally, the main fit took the core fit with the minimum error as the true fit.
\end{abstract}

\title{
Core fit
}

Considering all excitation and emission wavelengths, a linear regression for 5 algal groups had to be carried out with $4(7 \times 5)$ matrices. In order to save computer time, the observation that fluorescence at 600 and 620 nm mainly results from red cyanobacteria and Cryptophyta was utilised to solve the problem in 2 steps. Thus, in a first step, the algal concentrations $a_{g}, \lambda_{\text {em }}$ were calculated from the signals obtained from the 650 and $685 \mathrm{~nm}$ detectors by minimising the error sum.

The $a_{\mathrm{g}, \lambda \mathrm{em}}$ is determined by linear regression. This enables the calculation of the fluorescence signal expected at 600 and $620 \mathrm{~nm}$ resulting from 3 groups, namely the green, blue and brown groups. These fluorescence signals are subtracted from the measured signals at 600 or $620 \mathrm{~nm}$, respectively.

The $a_{g, \lambda e m}$ for the green, blue and brown groups and the $a_{g, \lambda e m}$ for the red cyanobacteria and the Cryptophyta may include unlikely solutions. Such an unlikely solution could be negative values of the $a_{g, \lambda e m}$. Therefore, unlikely solutions were eliminated before the results of the core fit were handed over to the main fit.

\section{Main fit}

To find the final solution for $\mathbf{a}_{685,1685,} \boldsymbol{a}_{650,1650}$ and $\boldsymbol{a}_{600,620,1600,620}$ the estimation error was defined as follows:

$$
\chi_{1685,1650}{ }^{2}=\chi_{685,1685^{2}}+\chi_{650,1650^{2}}+\chi_{600,620,1600,620}^{2}
$$

A simplex algorithm (Nelder \& Mead 1965) was used to minimise $\chi_{1685,1650}{ }^{2}$ of Eq. (A32) by variation of the blue cyanobacterial norm curves. The set of likely $\mathbf{a}_{\mathrm{g}, \lambda \mathrm{em}}$ values obtained with the norm curve that gave the minimum $\chi_{1685,1650}{ }^{2}$ was accepted as the final solution.

Editorial responsibility: Paul Harrison,

Kowloon, Hong Kong, SAR
Submitted: July 2, 2003; Accepted: February 10, 2004

Proofs received from author(s): March 22, 2004 